\title{
Differential Effects of Two Chronic Diazepam Treatment Regimes on Withdrawal Anxiety and AMPA Receptor Characteristics
}

\author{
Claire Allison*,' and Judith A Pratt' \\ 'Department of Physiology and Pharmacology, Strathclyde Institute for Biomedical Sciences, University of Strathclyde, Glasgow, UK
}

\begin{abstract}
Withdrawal from chronic benzodiazepines is associated with increased anxiety and seizure susceptibility. Neuroadaptive changes in neural activity occur in limbo-cortical structures although changes at the level of the $G_{A B A}$ receptor do not provide an adequate explanation for these functional changes. We have employed two diazepam treatment regimes known to produce differing effects on withdrawal aversion in the rat and examined whether withdrawal-induced anxiety was accompanied by changes in AMPA receptor characteristics. Rats were given 28 days treatment with diazepam by the intraperitoneal (i.p.) route $(5 \mathrm{mg} / \mathrm{kg}$ ) and the subcutaneous (s.c.) route $(15 \mathrm{mg} / \mathrm{kg})$. Withdrawal anxiety in the elevated plus maze was evident in the group withdrawn from chronic s.c. diazepam (relatively more stable plasma levels) but not from the chronic i.p. group (fluctuating daily plasma levels). In the brains of these rats, withdrawal anxiety was accompanied by increased $\left[{ }^{3} \mathrm{H}\right] \mathrm{Ro} 488587$ binding in the hippocampus and thalamus, and decreased GluRI and GluR2 subunit mRNA expression in the amygdala (GluRI and GluR2) and cortex (GluRI). The pattern of changes was different in the chronic i.p. group where in contrast to the chronic s.c. group, there was reduced $\left[{ }^{3} \mathrm{H}\right] \mathrm{Ro} 0488587$ binding in the hippocampus and no alterations in GluRI and GluR2 subunit expression in the amygdala. While both groups showed reduced GluRI mRNA subunit expression in the cortex overall, only the agranular insular cortex exhibited marked reductions following chronic i.p. diazepam. Striatal GluR2 mRNA expression was increased in the i.p. group but not the s.c. group. Taken together, these data are consistent with differential neuroadaptive processes in AMPA receptor plasticity being important in withdrawal from chronic benzodiazepines. Moreover, these processes may differ both at a regional and receptor function level according to the behavioral manifestations of withdrawal.
\end{abstract}

Neuropsychopharmacology (2006) 31, 602-619. doi: I0.1038/sj.npp. I300800; published online 22 June 2005

Keywords: benzodiazepine; synaptic plasticity; drug dependence; glutamate receptors; hippocampus; amygdala

\section{INTRODUCTION}

The benzodiazepines (BZs) including drugs such as diazepam (DZP) are used in the treatment of anxietyrelated disorders. However, dependence develops with longterm use, even at low to moderate (ie therapeutic) doses. This is characterized by tolerance to their sedative, muscle relaxant, and anticonvulsant effects and a characteristic withdrawal syndrome on cessation of treatment (Nutt, 1986; Woods et al, 1992, 1995).

Knowledge of the neural mechanisms underlying the development of $\mathrm{BZ}$ dependence remains incomplete. The $\mathrm{GABA}_{\mathrm{A}}$ receptor, being the pharmacological locus of $\mathrm{BZ}$ action, has been the focus of studies to date, although

*Correspondence: Dr C Allison, Department of Physiology and Pharmacology, Strathclyde Institute for Biomedical Sciences, University of Strathclyde, Taylor Street, Glasgow G4 ONR, UK, Tel: + 44 (0) I4 I 548 4I02, Fax: + 44 (0) |4| 552 2562,

E-mail: claire.allison@strath.ac.uk

Received 13 October 2004; revised 5 May 2005; accepted 6 May 2005 Online publication: 18 May 2005 at http://www.acnp.org/citations/ Npp05 I 805040440/default.pdf no clear view on its role has emerged. We have previously used functional brain mapping methods to identify neural circuitry recruited during $\mathrm{BZ}$ tolerance and withdrawal and investigated changes at the level of the $\mathrm{GABA}_{\mathrm{A}}$ receptor in the identified regions. 2-deoxyglucose autoradiography studies revealed regionally heterogeneous rates of tolerance to the depressant effect of DZP on glucose use in cortical and limbic structures, particularly those of the Papez circuit (Laurie and Pratt, 1989). Moreover, common structures were activated during withdrawal (Laurie and Pratt, 1993). Despite these brain structures displaying changes in functional activity (Laurie and Pratt, 1989, 1993), they did not exhibit alterations in $\mathrm{GABA}_{\mathrm{A}}$ receptor binding properties in complementary receptor autoradiography studies (Brett and Pratt, 1995). These studies do not however rule out the possibility that changes in $\mathrm{GABA}_{\mathrm{A}}$ receptor subunit gene expression may confer alterations in $\mathrm{GABA}_{\mathrm{A}}$ receptor function in $\mathrm{BZ}$ dependence. However, there is conflicting evidence for changes in these subunits as being responsible for the changes in neural activity demonstrated during $\mathrm{BZ}$ tolerance and withdrawal (Heninger et al, 1990; Kang and Miller, 1991; 
O’Donovan et al, 1992a, b; Tietz et al, 1993; Zhao et al, 1994; Impagnatiello et al, 1996; Holt et al, 1996, 1999; Pratt et al, 1998; Arnot et al, 2001), although this may be due to both methodological and procedural differences between these studies, including the use of different BZs in widely differing treatment regimes.

Thus, no clear consensus has been reached as to the contribution of changes at the level of the $\mathrm{GABA}_{\mathrm{A}}$ receptor to the neuroadaptive mechanisms in $\mathrm{BZ}$ dependence and it might be that changes at the level of this receptor are inadequate in themselves as an explanation. It is entirely possible that neuroadaptations in other receptor systems could be involved in the development of BZ dependence. Indeed, it has been hypothesized that as part of compensatory mechanisms to BZ-induced chronic enhancement of GABAergic inhibition, excitatory mechanisms (including the glutamatergic system) become more sensitive (Stephens, 1995). This sensitization could result in a new balance between excitatory and inhibitory neurotransmission becoming apparent, which gives rise to tolerance to the acute pharmacological effects of the BZs and the expression of withdrawal symptoms on cessation of treatment, including increased anxiety and also seizure activity.

Glutamate is a key candidate for changes in excitatory transmission mechanisms and BZ dependence (Stephens, 1995; Allison and Pratt, 2003): firstly, since there are defined neuroanatomical relationships between glutamatergic and GABAergic neurons in the CNS and, secondly, because of the pivotal role of glutamatergic neurotransmission in mediating many forms of synaptic plasticity such as LTP, kindling events, and sensitization. Of particular relevance is the differential involvement of the AMPA and NMDA glutamate receptor subtypes in the development and expression of these phenomena.

A reduction in NMDA receptor-mediated transmission in the CA1 region of the hippocampus coupled with reductions in NR2B subunit mRNA and protein expression have been reported following withdrawal from chronic flurazepam treatment (Van Sickle et al, 2002). Several studies have also provided evidence for a role for NMDA receptor antagonists in blocking the behavioral components of BZ tolerance and withdrawal (Steppuhn and Turski, 1993; File and Fernandes, 1994; Koff et al, 1997; Tsuda et al, 1998a, b). However, the contribution of AMPA receptors is less well explored. One group has suggested differential involvement of NMDA and AMPA receptors in DZP withdrawal, with AMPA receptor mechanisms being critical for initiating the withdrawal symptoms (Steppuhn and Turski, 1993), akin to their role in other forms of synaptic activity such as LTP. While additionally, evidence from studies in which large doses of BZs have been administered has provided further support for the involvement of alterations in AMPA receptor properties, particularly in the hippocampus, following BZ withdrawal (Izzo et al, 2001; Van Sickle and Tietz, 2002; Van Sickle et al, 2004).

We have also recently reported that withdrawal from chronic subcutaneous (s.c.) but not intraperitoneal (i.p.) DZP increases AMPA receptor binding in mouse hippocampus and amygdala (Allison et al, 2005) consistent with a hypothesis that neuroadaptive changes at the level of the AMPA receptor are involved in the differential effects of these treatment regimes on behavioral measures of with- drawal (Ward and Stephens, 1998; Dunworth and Stephens, 1998; Dunworth et al, 2000). However, neurochemical measures were not directly correlated with behavior in this study and changes in AMPA receptor subunit expression that could affect the functionality of the receptor were not investigated.

The present study was designed to test the hypothesis that neuroadaptive changes occur at the level of the AMPA receptor during DZP withdrawal in rats, specifically, whether regionally selective changes in AMPA receptor binding and GluR1 and GluR2 AMPA receptor subunit mRNAs accompanied withdrawal-anxiety in rats subjected to two different DZP treatment protocols that produce differential effects on the aversive effects of DZP withdrawal (Allison et al, 2002).

\section{METHODS}

Two separate experiments were carried out to investigate whether withdrawal from chronic i.p. or s.c. daily DZP dosing regimens produced signs of anxiety and evoked regionally selective alterations in AMPA receptor characteristics in rat brain.

\section{Animals and Experimental Design}

Male hooded Long Evans rats (Harlan, UK), weighing 200$300 \mathrm{~g}$ at the start of the studies ( $n=8$ per group), were randomly assigned to treatment groups shown in the table below. Animals were housed in temperature $\left(21 \pm 2{ }^{\circ} \mathrm{C}\right)$ - and humidity (45-65\%)-regulated rooms, maintained on a $12 \mathrm{~h}$ light-dark cycle (lights on at 0600) and allowed free access to food and water. All experiments were carried out in accordance with the UK Animals (Scientific Procedures) Act, 1986 and associated guidelines.

\begin{tabular}{|c|c|c|c|}
\hline Experiment & $\begin{array}{l}\text { Experimental } \\
\text { group }\end{array}$ & Chronic treatment & $\begin{array}{c}\text { Time (h) } \\
\text { from last } \\
\text { injection } \\
\text { (test) }\end{array}$ \\
\hline \multirow[t]{2}{*}{ I } & i.p. VEH & $\begin{array}{l}28 \text { days daily i.p. vehicle } \\
(1 \mathrm{ml} / \mathrm{kg})\end{array}$ & 24 \\
\hline & i.p. DZP & $\begin{array}{l}28 \text { days daily i.p. DZP } \\
(5 \mathrm{mg} / \mathrm{kg})\end{array}$ & 24 \\
\hline \multirow[t]{2}{*}{2} & s.c. VEH & $\begin{array}{l}28 \text { days daily s.c.. vehicle } \\
(1 \mathrm{ml} / \mathrm{kg})\end{array}$ & 48 \\
\hline & s.c. DZP & $\begin{array}{l}28 \text { days daily s.c. DZP } \\
(15 \mathrm{mg} / \mathrm{kg})\end{array}$ & 48 \\
\hline
\end{tabular}

At $24 \mathrm{~h}$ (day 29 in the i.p. groups) or $48 \mathrm{~h}$ (day 30 in the s.c. groups) following their last daily injection, all animals were tested on the elevated plus maze (EPM). All animals were killed immediately after the test period and their brains were removed and frozen in isopentane before being stored at $-70^{\circ} \mathrm{C}$ until required for receptor autoradiography and in situ hybridization (ISH). 
The chronic s.c. DZP treatment regimen employed ( $15 \mathrm{mg} / \mathrm{kg} /$ day s.c. for 28 days) is based on studies by other groups in both rats (Fernandes et al, 1999; Arnot et al, 2001) and mice (Steppuhn et al, 1993; Ward and Stephens, 1998; Dunworth et al, 2000), with the intention of producing relatively more stable plasma levels of DZP than the i.p. treatment regimen. The acute s.c. injection route (with a 50:50 DMSO to propylene glycol vehicle) has previously been shown to produce higher brain concentrations of DZP over a longer time period (Fernandes et al, 1999) when compared to the i.p. injection route in rats (Friedman et al, 1986). Additionally, in our hands, acute s.c. injection of DZP in a sesame oil vehicle results in a plasma elimination halflife $\left(t_{1 / 2}\right)$ of $3.18 \mathrm{~h}$ in the rat, with plasma concentrations of DZP being minimal after $24 \mathrm{~h}$ but undetectable after $48 \mathrm{~h}$ (Allison et al, 2002). This contrasts with the plasma elimination half-life of $0.88 \mathrm{~h}$ following acute i.p. injection of $5 \mathrm{mg} / \mathrm{kg} \mathrm{DZP}$ in the rat (closely paralleled by an elimination half-life in the brain of $0.89 \mathrm{~h}$; Friedman et al, 1986). Taken together, this suggests that our chronic s.c. regimen will produce fewer fluctuations in plasma and brain DZP levels than our chronic i.p. regimen. Behavioral testing and measurements of AMPA receptor properties were carried out at different specific time points following cessation of the chronic treatments. The time point of $24 \mathrm{~h}$ for the i.p. groups was selected on the basis of results from previous tolerance and withdrawal studies in our laboratory using the same i.p. DZP treatment protocol that produces tolerance to locomotor depressant and anticonvulsant effects and to regionally selective alterations in local cerebral glucose utilization (File, 1985; Gonsalves and Gallager, 1987; Laurie and Pratt, 1989; Pratt et al, 1998). The time point of $48 \mathrm{~h}$ after DZP discontinuation was chosen for the s.c. groups to take into account the fact that the elimination of DZP takes longer after s.c. injection, thus ensuring as much as possible that the plasma levels of DZP were minimal (Allison et al, 2002).

\section{Drugs}

DZP (Sigma, UK) at a dose of $5 \mathrm{mg} / \mathrm{kg}$ for i.p. injection was dispersed in a vehicle of $1 \% \mathrm{v} / \mathrm{v}$ Tween 20 in $0.9 \% \mathrm{w} / \mathrm{v}$ saline and suspended by sonication. DZP ( $15 \mathrm{mg} / \mathrm{kg})$ for s.c. injection was suspended in a sesame oil vehicle (15 mg of DZP per $\mathrm{ml}$ of oil) with sonication. All injections were given in a volume of $1 \mathrm{ml} / \mathrm{kg}$ of body weight.

\section{Behavioral Assessment of Anxiety}

The EPM test used in these studies to assess the anxiety state of the animals was that used by Allison et al (2002) and was based on that used by Handley and Mithani (1984) and Pellow et al (1985). The maze consisted of two opposite open arms measuring $9 \times 44 \mathrm{~cm}$ with a $3 \mathrm{~cm}$ lip and two opposite enclosed arms measuring $9 \times 44 \times 15 \mathrm{~cm}$ extending from a central area measuring $9 \times 9 \mathrm{~cm}$. The floor and walls of the arms and the central area were constructed of black Perspex. The maze was raised $1 \mathrm{~m}$ from the floor level. Behavioral testing was carried out in a dimly lit room. Animals were brought into the test room in their home cages immediately prior to the start of the test period and then placed on the central platform of the maze facing an open arm. A 10 min test duration was employed, after which the animal was removed to be killed. The maze was thoroughly cleaned with a $1 \%$ Hibitane solution and dried between subjects. All sessions were recorded on video using a ceiling-mounted video camera linked to a VCR and either a monitor or a computer loaded with EthoVision software in an adjacent room.

The behaviors monitored included number of entries and time spent in the open and closed arms of the maze, with arm entries being defined as an entry of all four paws into an arm. The ratio of open to total arm entries (for both time and number) is considered to be a measure of the anxiety state of the animal, such that the more anxious the animal, the closer this ratio approaches zero. The measurement of the total number of arm entries during the test period also gives a measure of the general locomotor activity of the subject and allows this measure to be ruled out as a factor in the test (Cruz et al, 1994; Fernandes and File, 1996; Rex et al, 1996). Risk assessment behaviors were also scored including frequency of rearing in the maze (with rearing being defined as an event where the animal balances on its hind paws), stretch-attend postures (SAPs; exploratory body postures where the rat stretches forward and retracts to its original position without actually moving forward), and head dipping (defined as an exploratory forward head/ shoulder movement over the side of the maze and down toward the floor). All of these exploratory behaviors can be distinguished as 'protected', that is, occurring on or from the relative security of the closed arm or central platform, or 'unprotected', that is, occurring on the exposed open arms of the maze (Dawson and Tricklebank, 1995), and also provide additional 'ethological' measures of the anxiety state of the animal on the maze.

\section{Receptor Autoradiography}

In the present study, the antagonist radioligand $\left[{ }^{3} \mathrm{H}\right] \mathrm{Ro} 48$ 8587 was employed to map the distribution of AMPA receptors throughout rodent brain and ascertain whether these regional patterns of distribution were altered following withdrawal from chronic treatment with different DZP regimens. This radioligand has been demonstrated to be more selective for the AMPA receptor than the best previously available quinoxalinedione antagonists (NBQX, CNQX, and YM 90K), with reported selectivity factors of $\sim 160$ - and >1000-fold for AMPA vs kainate and NMDA receptors, respectively (Mutel et al, 1998).

Preparation of brain sections for receptor autoradiography. The animals were killed by cervical dislocation, decapitated, and the brains removed and frozen in isopentane (Sigma, UK) precooled to $-42^{\circ} \mathrm{C}$. The frozen brains were then coated in embedding medium (Lipshaw Manufacturing Ltd) and stored at $-70^{\circ} \mathrm{C}$ until sectioning. Prior to sectioning, the brains were mounted on metal chucks with embedding medium and placed in a cryostat microtome (Bright Instruments) maintained at $-22^{\circ} \mathrm{C}$ for around $1 \mathrm{~h}$ to reach cryostat temperature. Coronal brain sections $(20 \mu \mathrm{m})$ were cut from selected brain areas of each rat brain and mounted onto room temperature, gelatinchrome alum-coated microscope slides. Sections were taken at $3.70 \mathrm{~mm}$ anterior to Bregma (corresponding to Figure 7 
of the rat brain atlas; Paxinos and Watson, 1997), $1.00 \mathrm{~mm}$ anterior to Bregma (Figure 14), $3.30 \mathrm{~mm}$ posterior to Bregma (Figure 31), and $4.80 \mathrm{~mm}$ posterior to Bregma (Figure 37). At each level, three coronal sections were collected for total binding measurements and two coronal sections for nonspecific binding measurements. The slides were air dried and packed into slide boxes containing silica gel, before being stored at $-70^{\circ} \mathrm{C}$ until required for the autoradiography experiments.

$\left.{ }^{3} \mathrm{H}\right] \mathrm{Ro} 488587$ autoradiography procedure. Brain sections were prepared for $\left[{ }^{3} \mathrm{H}\right] \mathrm{Ro} 488587$ autoradiography following a protocol modified from Mutel et al (1998). Based on results obtained from binding studies in rat coronal brain sections in our laboratory, which resulted in a $K_{\mathrm{D}}$ value of $3.54 \mathrm{nM}$ for this radioligand, a $5 \mathrm{nM}$ concentration of $\left[{ }^{3} \mathrm{H}\right] \mathrm{Ro} 48 \quad 8587$ was employed in the autoradiography experiments. Sections were preincubated for $20 \mathrm{~min}$ at room temperature in $50 \mathrm{mM}$ Tris- $\mathrm{HCl}$ buffer $(\mathrm{pH} 7.0)$. They were then air dried before incubation in $5 \mathrm{nM}\left[{ }^{3} \mathrm{H}\right] \mathrm{Ro} 48$ 8587 (NEN Life Science Products UK Ltd; specific activity $47 \mathrm{Ci} / \mathrm{mmol}$ ) in an assay buffer solution containing $100 \mathrm{nM}$ L-glycine, at $4{ }^{\circ} \mathrm{C}$ for $60 \mathrm{~min}$. Nonspecific binding was determined in the presence of $1 \mathrm{mM}$ quisqualic acid. Following incubation, radioligand solution was removed from the sections, which were then rinsed twice in ice-cold assay buffer for $30 \mathrm{~s}$, further rinsed in ice-cold assay buffer for $1 \mathrm{~min}$ followed by a short 2-3 s dip in distilled deionized water at $4{ }^{\circ} \mathrm{C}$ to remove any buffer salts. Brain sections were then air dried and placed in slide boxes containing silica gel at least overnight. They were then exposed to $\left[{ }^{3} \mathrm{H}\right]$-sensitive film (Hyperfilm- ${ }^{3} \mathrm{H}$, Amersham Pharmacia Biotech UK Ltd) in light tight cassette boxes, along with a set of precalibrated $\left[{ }^{3} \mathrm{H}\right]$ standards $(0-15160 \mathrm{nCi} / \mathrm{g} ;$ Amersham Pharmacia Biotech UK Ltd) for 7 days.

Quantification of autoradiograms. Autoradiograms generated by receptor autoradiography were analyzed using a computer-based densitometer (MCID, Canada). Measurements were made from the anterior cingulate cortex $(\mathrm{Cg} 1)$, the lateral orbital cortex (LO), the primary motor cortex (M1), secondary motor cortex (M2), the medial orbital cortex (MO), and prelimbic/infralimbic region of the prefrontal cortex (PrL/IL) at $3.70 \mathrm{~mm}$ anterior to Bregma (corresponding to Figure 7 of the rat brain atlas; Paxinos and Watson, 1997); from the nucleus accumbens core (AcC) and shell (AcSh), the agranular insular cortex (AI), dorsolateral caudate putamen $(\mathrm{DLCPu})$, and granular insular cortex (GI) at $1.00 \mathrm{~mm}$ anterior to Bregma (Figure 14); from the anterior part of the basolateral amygdaloid nucleus (BLA), dorsolateral part of the lateral amygdaloid nucleus (LaDL), laterodorsal thalamic nucleus (LDVL), medial amygdaloid nucleus (MePD/PV), piriform cortex (Pir), and reticular thalamic nucleus (Rt) at $3.30 \mathrm{~mm}$ posterior to Bregma (Figure 31); and from the oriens, molecular and radiatum areas of the CA1-CA3 regions of the hippocampus (CA1-3 OR, MOL, RAD), dentate gyrus (DG), lateral entorhinal cortex (LEnt), perirhinal cortex (PRh), and agranular (RSA) and granular (RSG) retrosplenial cortex at $4.80 \mathrm{~mm}$ posterior to Bregma (Figure 37 ). For each of the brain regions examined, bilateral optical density measurements were taken from three consecutive sections at the same level in the same animal and averaged (total binding measurements). Specific binding values were then obtained by subtraction of the nonspecific binding measures and these values were expressed in $\mathrm{nCi} / \mathrm{g}$ by reference to a standard curve created from measurements taken from the set of precalibrated $\left[{ }^{3} \mathrm{H}\right]$ standards exposed with each autoradiogram. The nonspecific binding for $\left[{ }^{3} \mathrm{H}\right]$ Ro48 8587 was very low (less than $2 \%$ of total binding), was almost indistinguishable from film background, and appeared to be homogenous throughout the brain regardless of brain region or treatment.

\section{In Situ Hybridization for AMPA Receptor Subunits}

The method of ISH was employed to visualize the expression of mRNA for GluR1 and GluR2 AMPA receptor subunits. The methods employed were based on those used by Wisden and Morris (1994).

Preparation of brain sections for in situ hybridization. Parallel $20 \mu \mathrm{m}$ coronal brain sections were cut from selected brain areas of each rat brain as for receptor autoradiography. Sections were thaw-mounted onto poly-L-lysine (Sigma, UK)-coated microscope slides at room temperature. At each level, two coronal brain sections were collected from each rat brain for total hybridization measurements and two control coronal brain sections were also collected at each level from at least one animal from each experimental group in the study.

Sections were allowed to dry at room temperature for at least $30 \mathrm{~min}$ before being placed in sterile glass racks. Racks of dry sections were then transferred to a sterile trough of ice-cold 4\% paraformaldehyde (PFA) solution for $5 \mathrm{~min}$ and then $1 \times$ phosphate-buffered saline (PBS) for several minutes. There then followed a series of dehydration steps: firstly, the rack of slides was placed in $70 \%$ ethanol for $5 \mathrm{~min}$, then $95 \%$ ethanol for $5 \mathrm{~min}$, and finally $100 \%$ ethanol for 5 min. All sections were then stored in AR-grade ethanol at $4{ }^{\circ} \mathrm{C}$ in a spark-free fridge until required for the ISH procedure.

Oligonucleotide probe labelling. Oligonucleotide probes (45-mers) complimentary to specific regions within the sequences of mRNA of GluR1 and GluR2 AMPA receptor subunits were employed (Keinanen et al, 1990). These probes were designed as Pan probes recognizing the sequences of mRNAs between transmembrane regions TM1 and TM2 of both flip and flop isoforms of the AMPA receptor subunits.

The probes were $3^{\prime}$-end labelled with the isotope $5-\alpha$ $\left[{ }^{35} \mathrm{~S}\right] \mathrm{dATP}$ (specific activity $1250 \mathrm{Ci} / \mathrm{mmol}$; NEN Life Science Products UK Ltd) and terminal deoxyribonucleotidyl transferase enzyme (TdT enzyme; Boehringer Mannheim) and incubated at $37^{\circ} \mathrm{C}$ for $1-3 \mathrm{~h}$. The enzyme reaction was then terminated by addition of $60 \mu \mathrm{l}$ diethylpyrocarbonate (DEPC)-treated water to the mixture and the probe was then purified by ethanol precipitation. The labelled probe was then eluted using an elution buffer (Quiaquick nucleotide removal kit, Qiagen). The extent of probe labelling was assessed using $\beta$ scintillation counting, and probes labelled from 100000 to 300000 d.p.m./ $\mu$ l were used for ISH. A $1 \mathrm{M}$ 
portion of dithiothreitol (DTT; Sigma) was added to the labelled probe aliquots to protect them from oxidative degeneration prior to use. Probes were then stored at $-20^{\circ} \mathrm{C}$ until required, but were used within 1 month of preparation.

In situ hybridization procedure. Brain sections were hybridized overnight at $42^{\circ} \mathrm{C}$ in a hybridization mixture comprising hybridization buffer $(50 \%$ deionized formamide, $20 \% 20 \times$ standard saline citrate $(20 \times \mathrm{SSC}=3 \mathrm{M}$ sodium chloride; $0.3 \mathrm{M}$ sodium citrate, $\mathrm{pH} 7$ ), $5 \% 0.5 \mathrm{M}$ sodium phosphate ( $\mathrm{pH} 7), 1 \% 0.1 \mathrm{M}$ sodium pyrophosphate, $2 \% 5 \mathrm{mg} / \mu \mathrm{l}$ polyadenylic acid, $10 \%$ dextran sulfate, volume adjusted to $50 \mathrm{ml}$ with DEPC-treated water), $5 \mathrm{ng} 5000 \mu^{-1}$ labelled probe, and $1 \mathrm{M}$ DTT in the proportion of $50: 1: 4$. Hybridization mixture $(200 \mu \mathrm{l})$ was applied to each slide and the sections then covered with parafilm. Parallel control sections were hybridized with labelled probe along with a four-fold excess of unlabelled probe. This resulted in levels of specific binding being reduced to background levels, with a uniform gray background where white and gray matter tracts were indistinguishable.

Following overnight hybridization, the parafilm was removed from each slide under $1 \times$ SSC and then washed in $1 \times \mathrm{SSC}$ at $60^{\circ} \mathrm{C}$ for $30 \mathrm{~min}$. Thereafter, the slides were washed in $1 \times$ SSC followed by $0.1 \times$ SSC at room temperature and dehydrated in ethanol gradients of 70 and $95 \%$. Once dry, sections were apposed to ${ }^{35} \mathrm{~S}$-sensitive film (Kodak Biomax MR-1 film, NEN Life Science Products UK Ltd) for 2-6 days and developed according to the manufacturer's instructions.

Quantification of autoradiograms. The autoradiograms were analyzed using a computer-based densitometer (MCID, Canada). Measurements were made from the same brain regions analyzed for receptor autoradiography. However, GluR1 and GluR2 subunits were only expressed in the pyramidal cell region of the hippocampus (CA1-3 PYR), not in the oriens (CA1-3 OR), radiatum (CA1-3 RAD), or molecular (CA1-3 MOL) regions. For each brain region examined, bilateral optical density measurements were taken from two consecutive sections at the same level in the same animal and averaged. Relative optical density (ROD) measurements for each brain region were then obtained by subtraction of the nonspecific binding measures, which were set for each individual section as an average of white matter readings on that section.

Statistical analysis. Data from both experiments were analyzed separately as they were performed at different times. Data for each of the various behavioral measures assessed on the EPM were analyzed by unpaired $t$-test with treatment group (chronic vehicle or chronic DZP) as a factor. A $p$-value of less than 0.05 defined statistical significance.

Values of specific $\left[{ }^{3} \mathrm{H}\right] \mathrm{Ro} 488587$ binding (nCi/g) and of ROD of GluR1 and GluR2 subunit mRNA expression measured in each experimental group for each brain region were analyzed using two-way ANOVA with treatment (VEH or DZP) and brain region as factors. Brain regions were hippocampus (CA1-3 and DG), amygdala (BLA, LaDL, and
$\mathrm{MePD} / \mathrm{PV}$ ), thalamus (LDVL and Rt), striatum (AcC, AcSh, and $\mathrm{DLCPu}$ ), limbic-associated cortex (AI, GI, RSA, and $\mathrm{RSGb}$ ), kindling/seizure-associated cortex (LEnt, Pir, and $\mathrm{PRh}$ ), motor cortex (M1 and M2), and prefrontal cortex (Cg1, LO, MO, and PrL/IL). Significant interactions between treatment and brain region were followed by post hoc analysis (Tukey's multiple comparison test).

\section{RESULTS}

\section{Elevated Plus Maze Test for Anxiety}

A number of spatiotemporal measures as well as ethologically based 'risk-assessment' behaviors were measured in the EPM to assess anxiety responses in rats on withdrawal from the chronic i.p. and s.c. DZP treatments employed (Table 1 and Figure 1).

In rats treated with $5 \mathrm{mg} / \mathrm{kg}$ i.p. DZP for 28 days and assessed for withdrawal-related behaviors $24 \mathrm{~h}$ following the last injection, no signs of increased anxiety were detected. No differences in either the number of arm entries in the maze, time spent in the open and closed arms, and the open: total time ratio were detected in the DZP-withdrawn group (Table 1 and Figure 1a). In addition, no differences were detected in other exploratory measures such as head dipping or rearing activity, or in 'risk assessment' behaviors in the DZP-withdrawn group (Table 1 and Figure 1c).

In contrast, in the rats treated s.c., there was a significant reduction ( $p=0.006 v s \mathrm{VEH}$, unpaired $t$-test) in the $\%$ time spent in the open arms of the maze and a corresponding significant increase ( $p=0.006 v s \mathrm{VEH}$, unpaired $t$-test) in the \% time spent in the closed arms of the maze in the DZP-withdrawn rats (Table 1). Furthermore, a significant reduction in the open: total time ratio $(p=0.005 v s \mathrm{VEH}$, unpaired $t$-test) was also detected in the DZP-withdrawn group (Figure $1 b$ ).

No significant changes were detected in the number of either open or closed arm entries in the EPM, the open : total arm entry ratio, or in the overall \% of open arm entries in the maze in the DZP-withdrawn group (Table 1). However, there was a trend, which approached statistical significance $(p=0.09)$, for a reduction in the $\%$ of open arm entries measured in the DZP-withdrawn rats.

With respect to the ethological measures of anxiety measured in the EPM in this analysis, significant changes in some of these factors indicative of increased levels of anxiety in the s.c. DZP-withdrawn rats were found. These included significant increases in the \% of 'protected' (ie performed from the relative safety of a closed arm or the central 'hub' portion of the EPM) SAPs being performed by the DZP-withdrawn group (Figure 1d; $p=0.03$ vs VEH group, unpaired $t$-test) and significant reductions in the total number of head dips performed (Table 1; $p=0.002 \mathrm{vs}$ VEH group, unpaired $t$-test). There was also a significant reduction in the number of episodes of open arm end exploration in the s.c. DZP-withdrawn group (VEH: $6.13 \pm 0.74$, DZP: $2.75 \pm 0.80 ; p=0.008$ vs VEH group).

A significant increase in rearing activity in the EPM was also detected in the s.c. DZP-withdrawn rats (Table 1; $p=0.02 v s \mathrm{VEH})$ indicating increased exploration in this group compared to the VEH-treated rats; however, other risk assessment measures such as \% 'protected' rears, 
Table I Selected Behavioral Parameters Measured in the EPM Test in Animals Withdrawn from Chronic Treatment with Diazepam (DZP) or Its Vehicle (VEH) either i.p. or s.c.

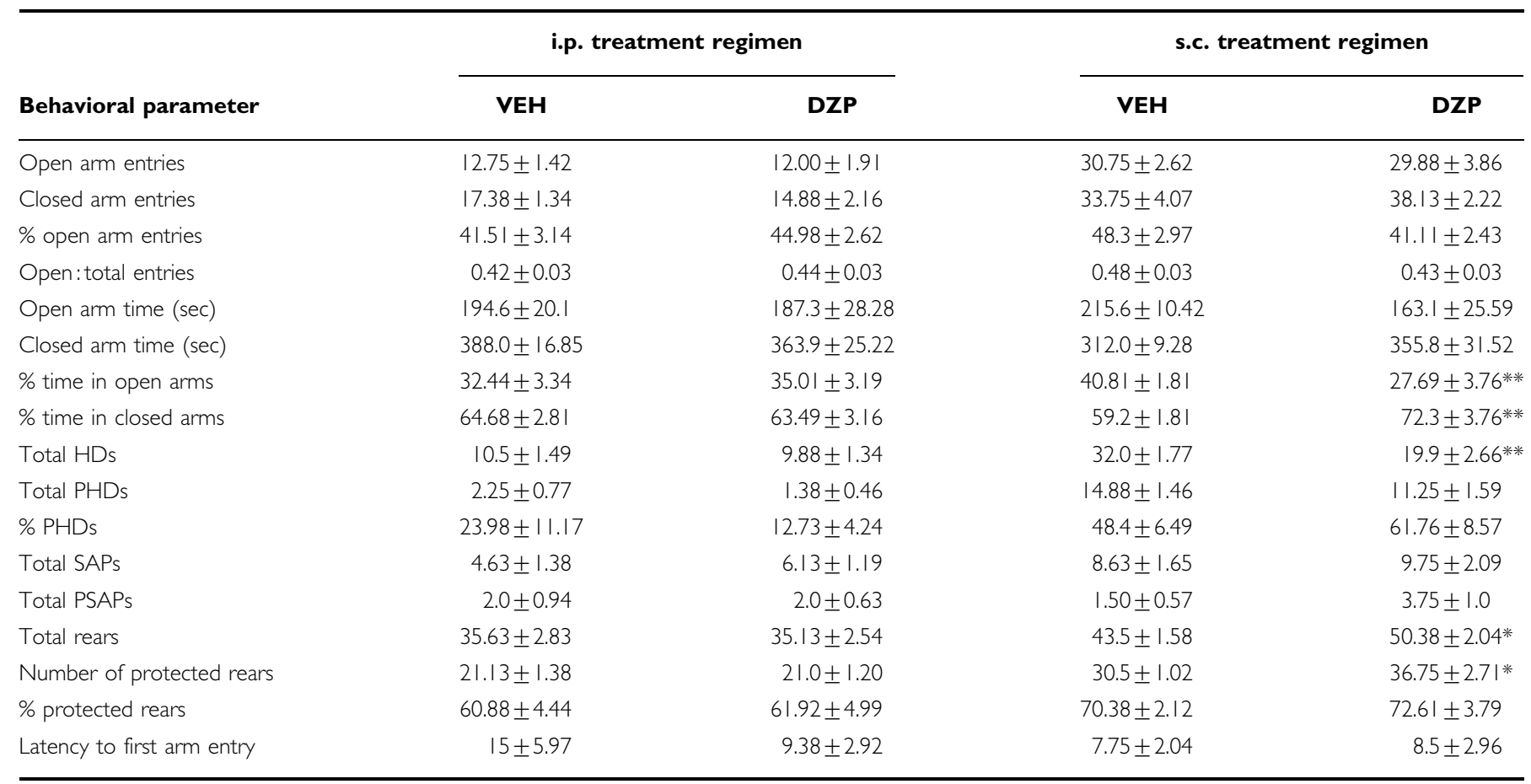

Data are expressed as mean \pm SEM ( $n=8$ per experimental group). $* p<0.05, * * p<0.01$ vs VEH (unpaired $t$-test).

HDs: head dips; PHDs: protected head dips; SAPs: stretch-attend postures; PSAPs: protected stretch-attend postures.
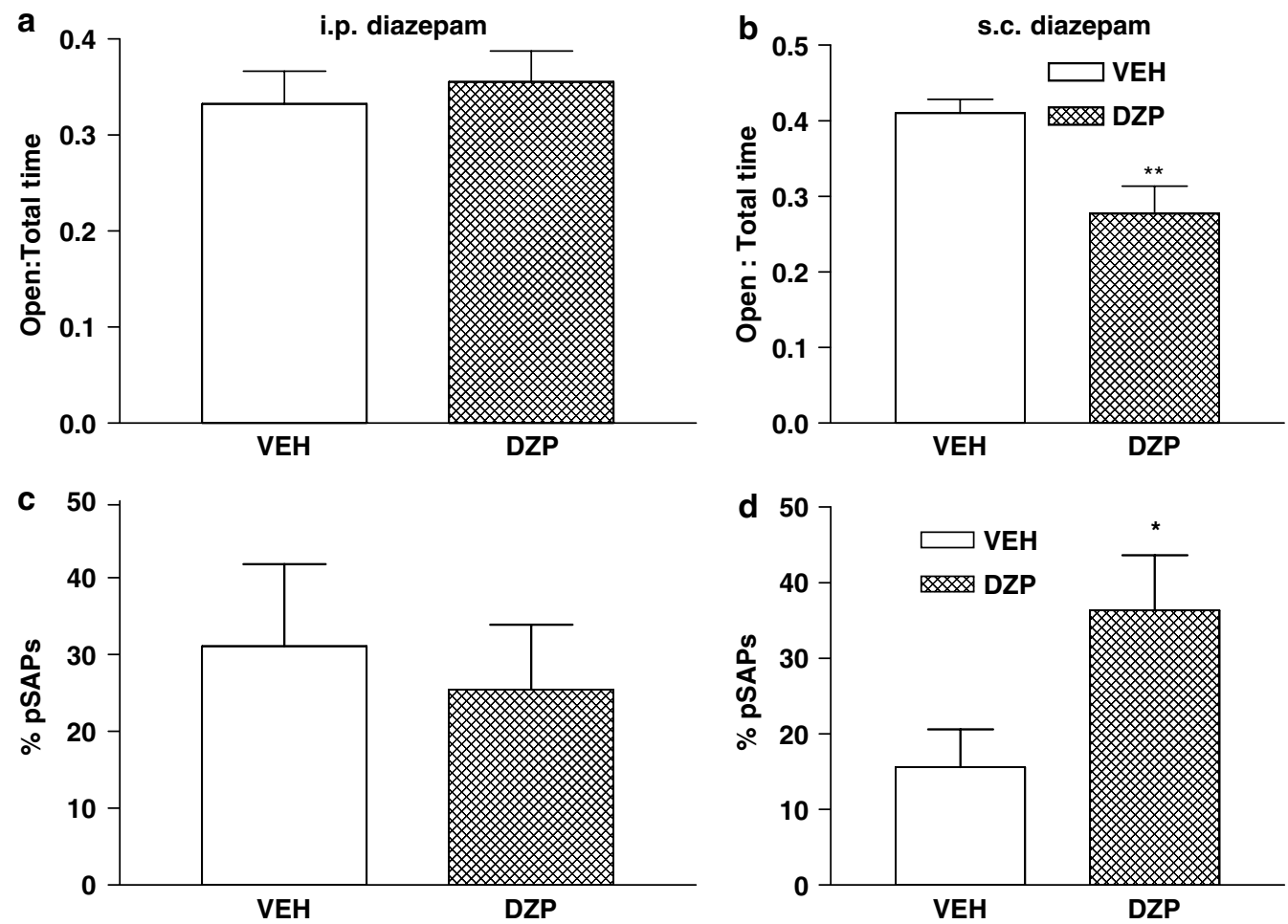

Figure I Effect of withdrawal from i.p. (a, c) and s.c. (b, d) DZP regimens on selected behaviors measured in the EPM test. (a, b) Ratio open/total time $(* * p=0.005$ vs VEH group, unpaired t-test); (c, d) \% of SAPs that were 'protected', that is, performed from the relative safety of a closed arm (* $p=0.03$ vs VEH group, unpaired $t$-test). Data are expressed as mean $\pm \operatorname{SEM}(n=8$ per experimental group). 
latency to first arm entry in the maze, total number of SAPs performed, and \% 'protected' head dips (Table 1) were not significantly altered in the DZP-withdrawn rats.

\section{Distribution of $\left[{ }^{3} \mathrm{H}\right] \mathrm{Ro} 488587$ Binding in Rat Brain}

The pattern of $\left[{ }^{3} \mathrm{H}\right] \mathrm{Ro} 488587$ binding was found to be heterogeneous in rat brain and comparable to that found by Mutel et al (1998) using the same radioligand, with the highest density of binding being apparent in hippocampus, outer layers of the cortex, striatum, reticular nucleus of the thalamus, and amygdaloid nuclei. Intermediate levels of binding were observed in other thalamic nuclei and in the mammillary body (Figure 2a and $b$ ). This pattern of binding is also consistent with that found when employing other AMPA receptor radioligands such as $\left[{ }^{3} \mathrm{H}\right] \mathrm{AMPA}$ (Monaghan et al, 1984; Rainbow et al, 1984; Olsen et al, 1987; Nielsen et al, 1988; Albin et al, 1992) and $\left[{ }^{3} \mathrm{H}\right] \mathrm{CNQX}$ (Nielsen et al, 1990).

\section{Effect of Withdrawal from Chronic Treatment with i.p. and s.c. Diazepam on $\left[{ }^{3} \mathrm{H}\right] \mathrm{Ro} 488587$ Binding in Rat Brain}

There were changes in specific $\left[{ }^{3} \mathrm{H}\right] \mathrm{Ro} 488587$ binding in the hippocampus and thalamus of rats 24 and $48 \mathrm{~h}$ after the last injection of DZP $(5 \mathrm{mg} / \mathrm{kg}$ i.p. or $15 \mathrm{mg} / \mathrm{kg}$ s.c., respectively). These changes were regionally specific since there were no significant effects of withdrawal from either
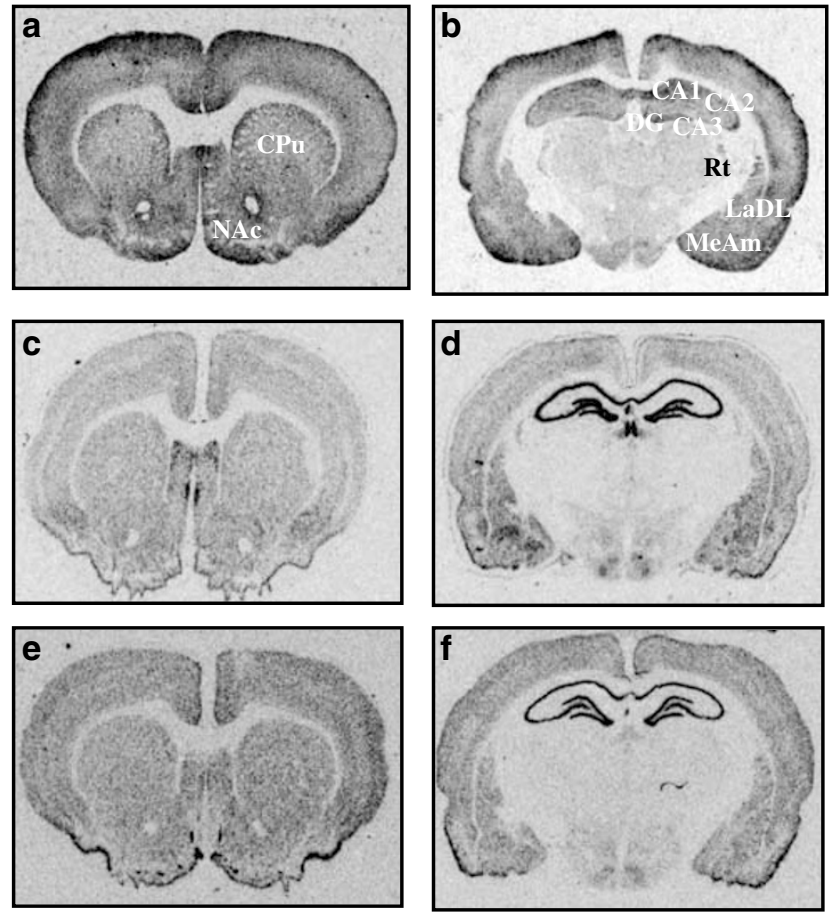

Figure 2 Regional distribution of specific $\left[{ }^{3} \mathrm{H}\right] \mathrm{Ro} 488587$ binding $(\mathrm{a}, \mathrm{b})$ and expression of GluRI (c, d) and GluR2 (e, f) in coronal rat brain sections corresponding to Figures 14 and 31 of the rat brain atlas (Paxinos and Watson, 1997). Abbreviations: CAI-3: CAI-3 subfields of the hippocampus; CPu: caudate putamen; DG: dentate gyrus of the hippocampus; LaDL: lateral amygdaloid nucleus, dorsolateral part; MeAm: medial amygdaloid nucleus; NAc; nucleus accumbens; Rt: reticular nucleus of the thalamus. chronic i.p. or s.c. DZP treatment on $\left[{ }^{3} \mathrm{H}\right]$ Ro48 8587 binding in other brain regions analyzed, which included amygdaloid nuclei, striatum, and cortical regions (Tables 2 and 3).

There were significant main effects of withdrawal from DZP in the hippocampus in both the i.p. (Figure 3a; $\mathrm{F}=7.18$ $(1,14), p=0.01)$ and the s.c. (Figure $3 \mathrm{~b} ; \mathrm{F}=4.56(1,14)$, $p=0.04)$ groups with respect to their relative controls. This was observed as an overall decrease and an increase in specific $\left[{ }^{3} \mathrm{H}\right] \mathrm{Ro} 488587$ binding within the hippocampus in the i.p. and s.c. DZP groups, respectively. However, there was no significant interaction between treatment and subregion in either the i.p. or s.c. groups $(\mathrm{F}=0.42(1,14)$, $p=0.93 ; \mathrm{F}=0.19(1,14), p=0.99$, respectively). Thus, there appears to be a modest change in binding in the hippocampus as a whole in response to withdrawal from both treatment regimens, with each subregion displaying an alteration in the range of 5-30 with respect to controls.

A significant main effect of DZP withdrawal in the s.c. DZP group in the thalamus was also apparent (Figure 3d; $\mathrm{F}=5.57(1,14), p=0.03)$. However, as in the hippocampus, no significant interaction between treatment and subregion was detected $(\mathrm{F}=0.12(1,14), p=0.72)$, suggesting that the response to treatment was similar within each subregion of the thalamus.

\section{Regional Distribution of GluR1 and GluR2 mRNA Expression in Rat Brain}

The patterns of GluR1 and GluR2 mRNA expression were found to be heterogeneous in rat brain and comparable to that found in previous studies (Keinanen et al, 1990; Pellegrini-Giampietro et al, 1991). Distribution of the mRNAs encoding these subunits exhibits widespread expression throughout the brain, most prominently in a variety of forebrain structures such as the olfactory bulb, septal nuclei, amygdala, hippocampus, and the habenula (Figure 2c-f). In the hippocampus, there is abundant expression of GluR1 and GluR2 mRNAs in the DG and pyramidal cell layer with no apparent gradient of expression between CA1 and CA3. Levels of both AMPA subunit mRNAs are low in the thalamic regions; however, in the amygdala, GluR1 and GluR2 mRNAs are highly expressed in all nuclei (Figure $2 \mathrm{~d}$ and $\mathrm{f}$ ).

This is consistent with previous ISH studies and also with studies examining $\left[{ }^{3} \mathrm{H}\right] \mathrm{AMPA}$ binding (Monaghan et al, 1984; Rainbow et al, 1984; Olsen et al, 1987; Nielsen et al, 1988 ) and $\left[{ }^{3} \mathrm{H}\right]$ Ro48 8587 binding (Mutel et al, 1998) to the AMPA receptor in rat brain.

\section{Effect of Withdrawal from Chronic Treatment with i.p. and s.c. Diazepam on Expression of AMPA Receptor Subunits in Rat Brain}

Regionally selective changes in the expression of GluR 1 and GluR2 subunit mRNA were found in cortical and amygdaloid regions of the rat brain 24 and $48 \mathrm{~h}$ following the last dose of i.p. and s.c. DZP, respectively.

\section{GluR1 mRNA Expression: Chronic i.p. DZP Regimen}

A significant reduction of around $40 \%$ relative to the vehicle controls in the expression of mRNA for the GluR1 subunit 
Table 2 Alterations in Specific $\left[{ }^{3} H\right]$ Ro48 8587 Binding and GluRI and GluR2 Subunit mRNA Expression in Selected Brain Regions Following Withdrawal from the i.p. DZP Treatment Regimen

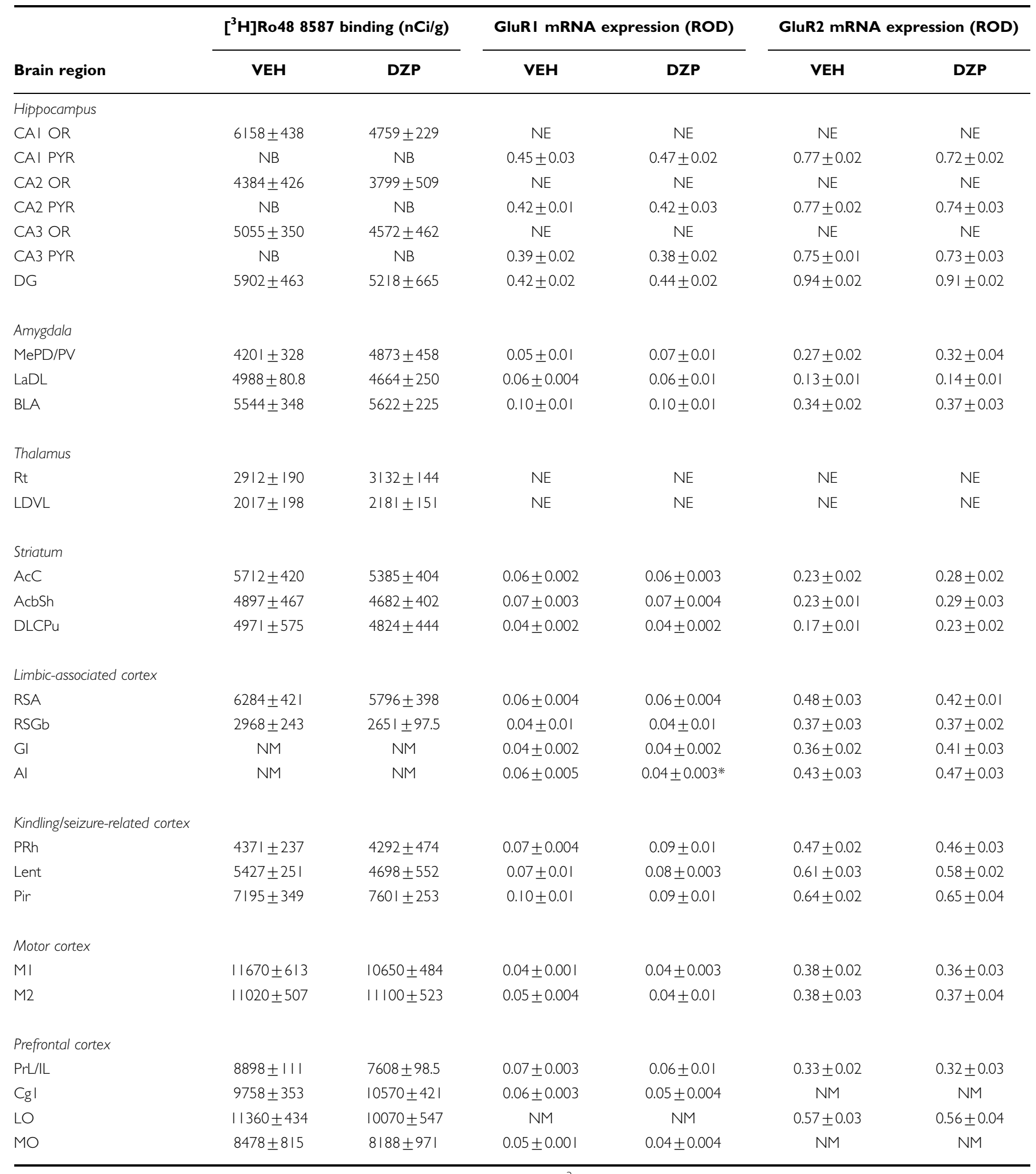

Two-way ANOVA revealed significant effects of DZP withdrawal in the hippocampus ( $\left[{ }^{3} \mathrm{H}\right] \mathrm{Ro} 488587$ binding), limbic-associated cortex (GluRI), and striatum (GluR2) overall. * $p<0.00$ I vs corresponding VEH value (two-way ANOVA followed by Tukey post hoc test). NB: no binding in that brain region; NE: subunit not expressed in that brain region; NM: not measured. See the Methods section for abbreviations. 
Table 3 Alterations in Specific $\left[{ }^{3} \mathrm{H}\right] \mathrm{Ro} 488587$ Binding and GluRI and GluR2 Subunit mRNA Expression in Selected Brain Regions Following Withdrawal from the s.c. DZP Treatment Regimen

\begin{tabular}{|c|c|c|c|c|c|c|}
\hline \multirow[b]{2}{*}{ Brain region } & \multicolumn{2}{|c|}{$\left[{ }^{3} \mathrm{H}\right]$ Ro48 8587 binding $(\mathrm{nCi} / \mathrm{g})$} & \multicolumn{2}{|c|}{ GluRI mRNA expression (ROD) } & \multicolumn{2}{|c|}{ GluR2 mRNA expression (ROD) } \\
\hline & VEH & DZP & VEH & DZP & VEH & DZP \\
\hline \multicolumn{7}{|l|}{ Hippocampus } \\
\hline CAI OR & $3133 \pm 274$ & $3344 \pm 416$ & NE & NE & NE & NE \\
\hline CAI PYR & NB & NB & $0.44 \pm 0.01$ & $0.43 \pm 0.01$ & $0.49 \pm 0.02$ & $0.50 \pm 0.01$ \\
\hline CA2 OR & $2784 \pm 216$ & $3237 \pm 160$ & NE & NE & NE & NE \\
\hline CA2 PYR & NB & NB & $0.51 \pm 0.02$ & $0.48 \pm 0.02$ & $0.51 \pm 0.02$ & $0.49 \pm 0.02$ \\
\hline CA3 OR & $3092 \pm 340$ & $3350 \pm 284$ & NE & NE & NE & NE \\
\hline CA3 PYR & NB & NB & $0.47 \pm 0.01$ & $0.44 \pm 0.01$ & $0.45 \pm 0.01$ & $0.45 \pm 0.01$ \\
\hline DG & $3051 \pm 478$ & $3485 \pm 619$ & $0.40 \pm 0.02$ & $0.42 \pm 0.01$ & $0.50 \pm 0.02$ & $0.48 \pm 0.01$ \\
\hline \multicolumn{7}{|l|}{ Amygdala } \\
\hline MePD/PV & $2486 \pm 223$ & $2570 \pm 488$ & $0.12 \pm 0.01$ & $0.10 \pm 0.02$ & $0.12 \pm 0.01$ & $0.09 \pm 0.01$ \\
\hline $\mathrm{LaDL}$ & $2013 \pm 241$ & $|78| \pm 4 \mid 4$ & $0.11 \pm 0.01$ & $0.10 \pm 0.01$ & $0.13 \pm 0.004$ & $0.11 \pm 0.009$ \\
\hline BLA & $1815 \pm 232$ & $2074 \pm 410$ & $0.15 \pm 0.003$ & $0.14 \pm 0.01$ & $0.12 \pm 0.003$ & $0.11 \pm 0.01$ \\
\hline \multicolumn{7}{|l|}{ Thalamus } \\
\hline Rt & $912.0 \pm 100$ & $1177 \pm 154$ & NE & NE & $\mathrm{NE}$ & NE \\
\hline LDVL & $|149 \pm 10|$ & $1507 \pm 160$ & $\mathrm{NE}$ & $\mathrm{NE}$ & $\mathrm{NE}$ & $\mathrm{NE}$ \\
\hline \multicolumn{7}{|c|}{ Limbic-associated cortex } \\
\hline RSA & $2947 \pm 541$ & $3355 \pm 335$ & $0.07 \pm 0.004$ & $0.06 \pm 0.002$ & $0.13 \pm 0.005$ & $0.12 \pm 0.004$ \\
\hline RSGb & $1258 \pm 224$ & $1611 \pm 169$ & $0.06 \pm 0.004$ & $0.05 \pm 0.003$ & $0.14 \pm 0.01$ & $0.14 \pm 0.01$ \\
\hline Gl & $4659 \pm 464$ & $4479 \pm 348$ & $0.06 \pm 0.003$ & $0.05 \pm 0.002$ & $0.16 \pm 0.004$ & $0.14 \pm 0.009$ \\
\hline Al & $4768 \pm 421$ & $4559 \pm 229$ & $0.08 \pm 0.005$ & $0.07 \pm 0.005$ & $0.17 \pm 0.01$ & $0.17 \pm 0.01$ \\
\hline \multicolumn{7}{|l|}{ Striatum } \\
\hline $\mathrm{AcC}$ & $1974 \pm 225$ & $1794 \pm 190$ & $0.09 \pm 0.003$ & $0.09 \pm 0.003$ & $0.11 \pm 0.002$ & $0.10 \pm 0.003$ \\
\hline AcSh & $1916 \pm 183$ & $1755 \pm 118$ & $0.12 \pm 0.01$ & $0.12 \pm 0.005$ & $0.11 \pm 0.01$ & $0.10 \pm 0.01$ \\
\hline DLCPu & $1965 \pm 133$ & $1828 \pm 136$ & $0.07 \pm 0.003$ & $0.07 \pm 0.002$ & $0.09 \pm 0.004$ & $0.09 \pm 0.004$ \\
\hline \multicolumn{7}{|c|}{ Kindling/seizure-associated cortex } \\
\hline PRh & $2591 \pm 306$ & $2732 \pm 193$ & $0.13 \pm 0.003$ & $0.13 \pm 0.004$ & $0.16 \pm 0.01$ & $0.16 \pm 0.01$ \\
\hline Lent & $2666 \pm 247$ & $2489 \pm 264$ & $0.10 \pm 0.004$ & $0.10 \pm 0.004$ & $0.19 \pm 0.005$ & $0.20 \pm 0.01$ \\
\hline Pir & $2828 \pm 275$ & $3174 \pm 409$ & $0.12 \pm 0.01$ & $0.11 \pm 0.004$ & $0.31 \pm 0.01$ & $0.29 \pm 0.01$ \\
\hline \multicolumn{7}{|l|}{ Motor cortex } \\
\hline $\mathrm{MI}$ & $4702 \pm 453$ & $4476 \pm 349$ & $0.06 \pm 0.003$ & $0.06 \pm 0.003$ & $0.16 \pm 0.01$ & $0.15 \pm 0.003$ \\
\hline M2 & $4880 \pm 360$ & $4587 \pm 367$ & $0.07 \pm 0.003$ & $0.07 \pm 0.005$ & $0.14 \pm 0.02$ & $0.14 \pm 0.005$ \\
\hline \multicolumn{7}{|l|}{ Prefrontal cortex } \\
\hline $\mathrm{PrL} / \mathrm{LL}$ & $3835 \pm 507$ & $3255 \pm 384$ & $0.10 \pm 0.005$ & $0.10 \pm 0.005$ & $0.16 \pm 0.01$ & $0.16 \pm 0.01$ \\
\hline $\mathrm{CgI}$ & $427| \pm 46|$ & $4288 \pm 304$ & $0.10 \pm 0.005$ & $0.09 \pm 0.004$ & $0.16 \pm 0.01$ & $0.14 \pm 0.005$ \\
\hline LO & $4261 \pm 433$ & $3874 \pm 443$ & $0.05 \pm 0.002$ & $0.05 \pm 0.003$ & $0.14 \pm 0.01$ & $0.14 \pm 0.01$ \\
\hline MO & $4189 \pm 481$ & $3533 \pm 414$ & $0.07 \pm 0.003$ & $0.06 \pm 0.007$ & $0.15 \pm 0.01$ & $0.14 \pm 0.005$ \\
\hline
\end{tabular}

Two-way ANOVA revealed significant effects of DZP withdrawal in the hippocampus and thalamus ([ $\left.{ }^{3} \mathrm{H}\right] \mathrm{Ro} 488587$ binding), limbic-associated cortex (GluRI), and amygdala (GluRI and GluR2). NB: no binding in that brain region; NE: subunit not expressed in that brain region. See the Methods section for abbreviations. 

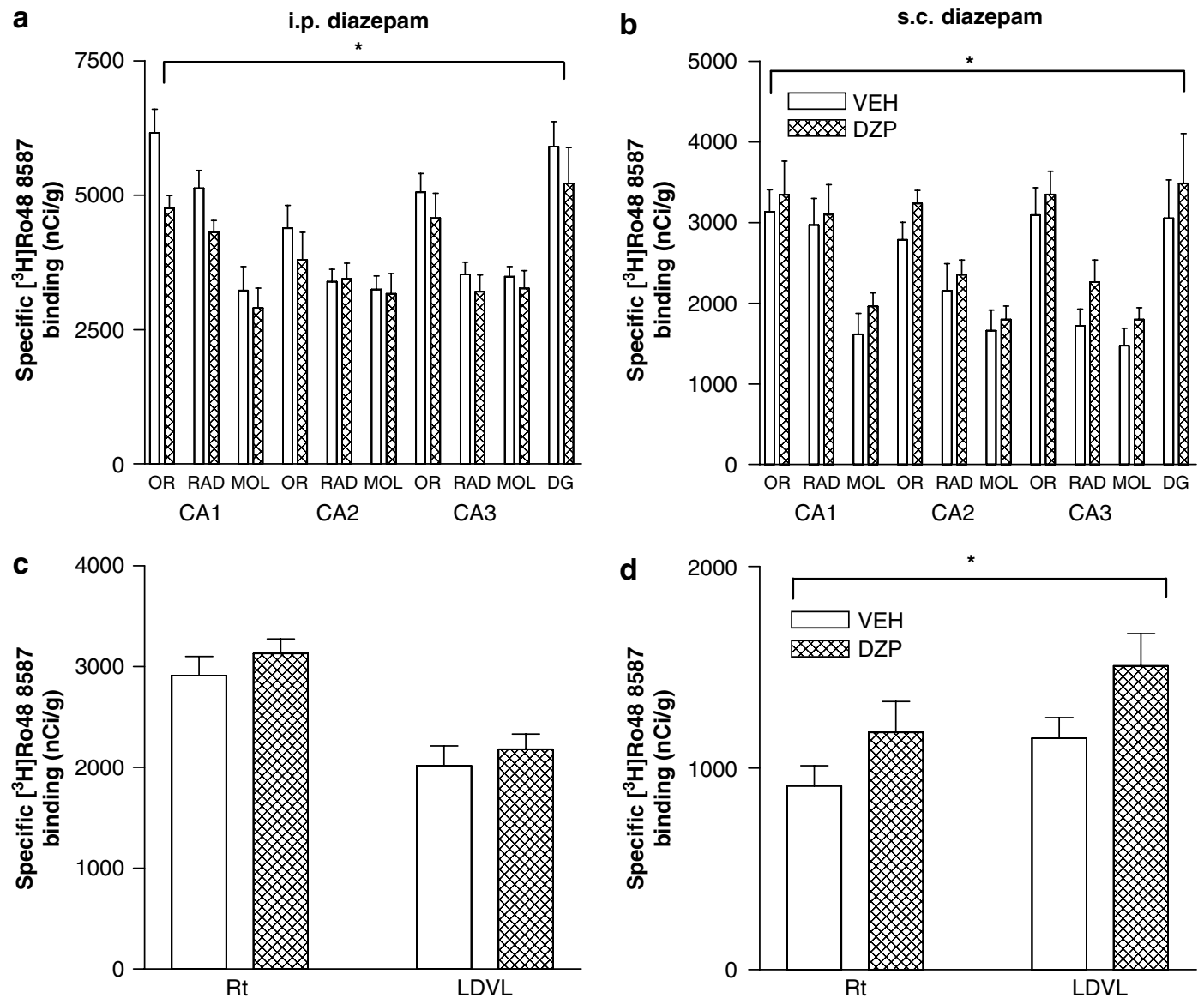

Figure 3 Effect of withdrawal from i.p. (a, c) and s.c. (b, d) DZP regimens on specific $\left[{ }^{3} \mathrm{H}\right]$ Ro48 8587 binding to the AMPA receptor in selected hippocampal and thalamic regions. Data are expressed as mean \pm SEM ( $\mathrm{nCi} / \mathrm{g} ; n=8$ per experimental group). There was a significant effect of DZP withdrawal $(* p<0.05$, two-way ANOVA). See the Methods section for abbreviations.

of the AMPA receptor was found in the AI (Figure 4a) in rats treated chronically with $5 \mathrm{mg} / \mathrm{kg}$ i.p. DZP.

Thus, analysis of GluR1 mRNA expression levels in limbic-associated cortical regions revealed a significant main effect of DZP withdrawal $(\mathrm{F}(1,14)=4.61 ; p=0.03)$, a significant main effect of subregion $(\mathrm{F}(1,14)=42.5$; $p<0.00$ ), and a significant interaction between these factors $(\mathrm{F}(1,14)=1.99 ; p=0.03)$. Post hoc analysis then revealed a significant decrease in GluR1 mRNA expression in the AI in the i.p. DZP group compared to control $(p=0.004)$, but not in other cortical regions measured (Figure $4 \mathrm{a}$ ).

There were also no significant effects of withdrawal from the i.p. DZP treatment regimen on GluR1 mRNA expression in any of the other brain regions analyzed (Table 2), including the amygdaloid regions (Figure 4c).

\section{GluR1 mRNA Expression: Chronic s.c. DZP Regimen}

In the s.c. DZP-treated rats, significant effects of treatment on GluR1 mRNA expression were detected in limbicassociated cortical regions and the amygdala, but not in the thalamus, hippocampus, and other cortical regions (Table 3). Thus, analysis of expression levels in limbicassociated cortical regions (Figure $4 \mathrm{~b}$; retrosplenial cortex, granular and agranular insular cortices) revealed a significant effect of DZP withdrawal overall $(\mathrm{F}(1,14)=$ $14.57 ; p<0.00)$, a significant main effect of subregion $(\mathrm{F}(1,14)=31.64 ; p<0.00)$ but no significant interaction between these factors $(\mathrm{F}(1,14)=1.99 ; p=0.03)$. Thus, there appears to be a modest change in expression in these cortical regions as a whole in response to withdrawal from s.c. DZP, in particular there is a trend for a reduction of around $15 \%$ in GluR1 mRNA expression in the DZP group in the retrosplenial agranular (RSA) and granular (RSGb) cortices as compared to vehicle controls (Figure $4 \mathrm{~b}$ and Table 3). However, post hoc analysis did not reveal any differences in GluR1mRNA expression in any of the individual limbic cortical regions in response to DZP withdrawal.

Analysis of GluR1 mRNA expression levels in the amygdala in the s.c. groups (Figure 4d and Table 3; medial, basolateral, and lateral dorsolateral nuclei) revealed a significant effect of DZP withdrawal overall $(\mathrm{F}(1,14)=$ 4.16; $p=0.047)$, a significant effect of subregion $(\mathrm{F}(1,14)=$ 7.43; $p<0.00)$ but no significant interaction between these factors $(\mathrm{F}(1,14)=0.05 ; p=0.98)$. Therefore, despite the trend for an overall reduction in GluR1 mRNA expression in the amygdala in the s.c. DZP-treated rats (Figure 4d), there were no significant effects in any of the individual nuclei measured. 

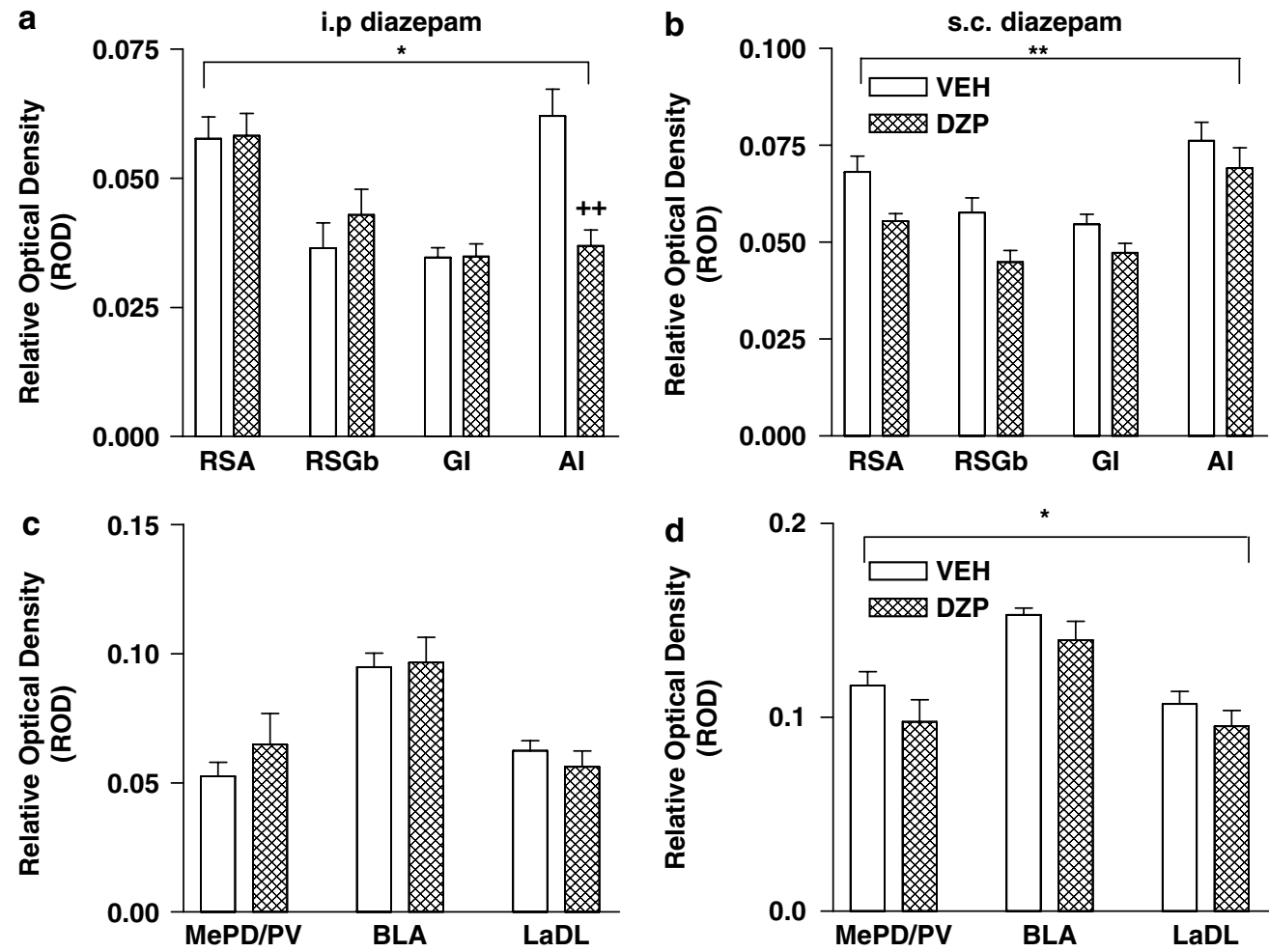

Figure 4 Effect of withdrawal from i.p. (a, c) and s.c. (b, d) DZP regimens on GluRI subunit mRNA expression in limbic-associated cortical regions and in selected amygdaloid nuclei. Data are expressed as mean \pm SEM ROD ( $n=8$ per experimental group). * $p<0.05$, ** $p<0.01$, significant effect of DZP withdrawal (two-way ANOVA). (a) Significant reduction in expression in DZP group in $\mathrm{Al}(++p<0.00 \mathrm{l}$ vs control, two-way ANOVA followed by Tukey post hoc test). See the Methods section for abbreviations.

\section{GluR2 mRNA Expression: Chronic i.p. DZP Regimen}

The pattern of withdrawal-induced changes in expression of GluR2 differed from that of GluR1 mRNA expression. Analysis of GluR2 mRNA expression levels in the striatum in the i.p. groups (Figure 5a and Table 2; $\mathrm{AcC}, \mathrm{AcSh}$, and dorsolateral caudate) revealed a significant main effect of DZP withdrawal $(\mathrm{F}(1,14)=16.27 ; p<0.00)$, a significant main effect of subregion $(\mathrm{F}(1,14)=8.05 ; p<0.00)$ but no significant interaction between DZP withdrawal and subregion $(\mathrm{F}(1,14)=0.02 ; p=0.98)$. Post hoc analysis revealed that despite an overall significant change in GluR2 mRNA expression in the striatum in the i.p. DZP-treated rats (Figure 5a), this increase was not statistically significant in any of the individual subregions measured. No significant effects of withdrawal from the i.p. DZP treatment regimen on GluR2 mRNA expression were detected in the amygdala (Figure 5c) or any of the other brain regions analyzed in this study (Table 2).

\section{GluR2 mRNA Expression: Chronic s.c. DZP Regimen}

In contrast to the i.p. treated groups, withdrawal from s.c. DZP produced a decrease of around $15-25 \%$ in GluR2 mRNA expression in the amygdaloid nuclei (Figure 5d). Analysis of expression levels in the amygdala overall revealed a significant effect of DZP withdrawal $(\mathrm{F}(1,14)=15.25 ; p<0.00)$, no significant effect of subregion $(\mathrm{F}(1,14)=2.43 ; p=0.08)$, and no significant interaction between these factors $(\mathrm{F}(1,14)=0.10 ; p=0.96)$. Unlike withdrawal from i.p. DZP, there were no overall changes in GluR2 subunit mRNA expression in the striatum following withdrawal from s.c. DZP treatment (Figure 5b). In addition, there were no significant effects of withdrawal from the s.c. DZP treatment regimen on GluR2 mRNA expression in any of the other brain regions analyzed in this study (Table 3).

\section{DISCUSSION}

\section{Behavioral Measure of Dependence}

The aim of the present study was to test the prediction that two different chronic DZP treatment regimes would produce distinct behavioral signs of withdrawal accompanied by regional differences in AMPA receptor characteristics. Using the EPM test of anxiety, withdrawal from a chronic s.c. DZP treatment regime $(15 \mathrm{mg} / \mathrm{kg})$ but not a chronic i.p. $(5 \mathrm{mg} / \mathrm{kg})$ regime produced increases in anxiety-related behaviors. In support of the original hypothesis, withdrawal anxiety was accompanied by regional differences in AMPA receptor characteristics in the hippocampus, thalamus, and amygdala.

The chronic s.c. DZP regime employed is one that produces more stable plasma levels of DZP than the i.p. regime used in the present study (Allison et al, 2002). The rats withdrawn from this s.c. regime showed significant anxiety on withdrawal. Of the spatiotemporal measures 

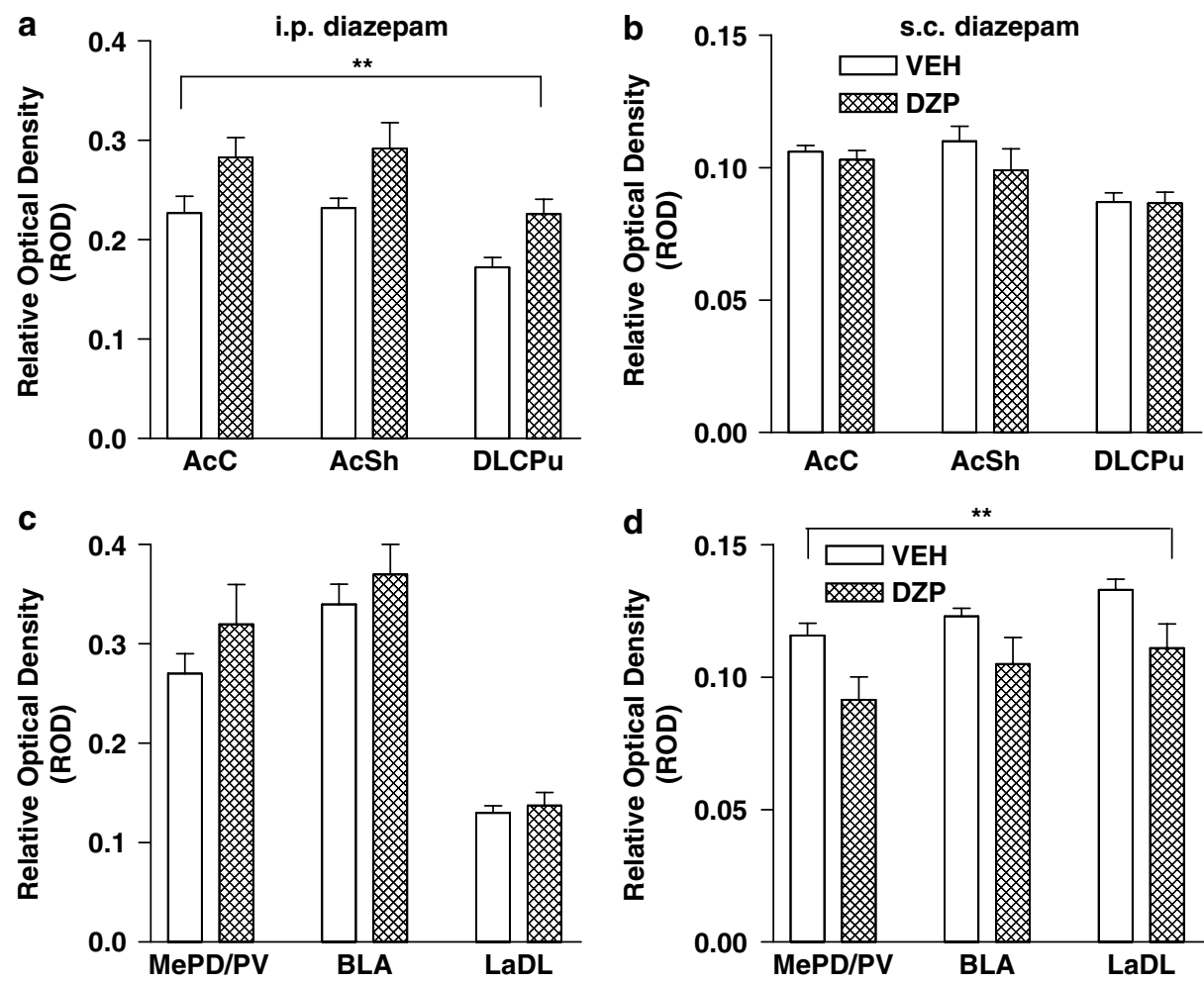

Figure 5 Effect of withdrawal from i.p. (a, c) and s.c. (b, d) DZP regimens on GluR2 subunit mRNA expression in selected amygdaloid nuclei and striatal regions. Data are expressed as mean $\pm \operatorname{SEM} R O D(n=8$ per experimental group). $* * p<0.01$, significant effect of DZP withdrawal (two-way ANOVA). See the Methods section for abbreviations.

scored, there was a significant reduction in the \% of time spent in the open arms of the maze with a corresponding increase in the $\%$ of time spent in the closed arms. This was also reflected in a significant decrease in the open/total ratio for time. Total arm entries remained unchanged suggesting that anxiety-related measures were occurring in the absence of concomitant changes in locomotor activity.

Measurement of ethological behaviors in the EPM such as head dipping, SAPs, rearing, and end exploration ('risk assessment' behaviors; Cruz et al, 1994; Shepherd et al, 1994; Dawson and Tricklebank, 1995; Rodgers and Johnson, 1995) also revealed behaviors consistent with increased anxiety in the s.c. DZP-withdrawn group. Thus, there was an increase in the proportion of protected SAPs (Figure 1c) although (importantly) there was no significant change in the overall number of these behaviors performed (Table 1). Furthermore, there was a significant reduction in the number of episodes of end exploration on the open arms of the maze in this group.

In contrast to the chronic s.c. treatment regime, the chronic i.p. schedule did not result in increased anxiety behaviors on withdrawal. Interestingly, increased anxiety on withdrawal from BZs has often been difficult to detect in animal studies and may be influenced by a variety of factors (Baldwin and File, 1989; File, 1989; Costall et al, 1990; Wright $e t a l, 1992)$. Nevertheless, the i.p. treatment is likely to have produced neuroadaptive changes reflecting dependence since tolerance develops to its locomotor depressant and anticonvulsant effects and to the regionally selective alterations in local cerebral glucose utilization (File, 1985;
Gonsalves and Gallager, 1987; Laurie and Pratt, 1989; Pratt et al, 1998).

An alternative explanation for the lack of withdrawal anxiety is that because of the rapid pharmacokinetics of DZP administered i.p. in the rat, this route of administration results in unintentional daily 'withdrawal' events. DZP when injected i.p. in the rat is rapidly absorbed and eliminated (plasma $t_{1 / 2}=0.88 \mathrm{~h}$, brain $t_{1 / 2}=0.89 \mathrm{~h}$; Friedman et al, 1986), with no evidence for repeated injection significantly prolonging the serum $t_{1 / 2}$ of DZP compared to that after a single i.p. injection (Walker et al, 1998). Therefore, the present i.p. DZP treatment regimen is likely to produce rapid fluctuations in plasma DZP concentrations, with levels reaching a minimum $5 \mathrm{~h}$ after each daily i.p. injection. It is therefore possible that the rats experience daily spontaneous withdrawal events during the course of the chronic DZP treatment. This is consistent with evidence from mouse studies, which showed that repeated previous experience of withdrawal from DZP ameliorates the anxiogenic effect of withdrawal, while lowering seizure thresholds (Dunworth and Stephens, 1998; Ward and Stephens, 1998). Thus, in the present study, the rats undergoing the i.p. DZP treatment regimen may not have displayed overt anxiety-like behaviors since they had already undergone repeated daily withdrawals from the drug, resulting in an amelioration of the anxiogenic effect.

A further explanation for the lack of withdrawal anxiety in the i.p. DZP group may be the time point at which this behavior was measured. However, it is unlikely that the $24 \mathrm{~h}$ withdrawal was not protracted enough in our i.p. groups, 
since in experiments using the same DZP treatment protocol ( $5 \mathrm{mg} / \mathrm{kg}$ i.p. for 28 days), anxiogenic responses were not demonstrated on the EPM 72 or $120 \mathrm{~h}$ following discontinuation of DZP (Allison, 2002; open:total time ratios: $72 \mathrm{~h}$ withdrawal: VEH $0.31 \pm 0.02$, DZP $0.32 \pm 0.03$; 120 h withdrawal: VEH $0.27 \pm 0.04$, DZP $0.33 \pm 0.02)$. This does not exclude the possibility that behavioral signs of withdrawal could occur at time points before $24 \mathrm{~h}$. However, Izzo et al (2001), using a more severe escalating oral DZP dosing regimen, failed to show withdrawal anxiety at 12,24 , or $48 \mathrm{~h}$ after discontinuation; therefore, it is unlikely that our more modest dosing regimen would produce withdrawal anxiety before the $24 \mathrm{~h}$ time point.

In summary, these behavioral results suggest that the rats withdrawn from the chronic s.c. DZP treatment regimen experienced withdrawal anxiety, while the rats withdrawn from the i.p. DZP treatment regimen did not. This concurs with results obtained in our previous study, which demonstrated that flumazenil-precipitated withdrawal from these same DZP treatment regimens produced a conditioned place aversion after s.c. but not i.p. DZP (Allison et al, 2002). These effects on withdrawal anxiety and aversion may be the result of these treatment regimens producing either a single withdrawal event (s.c. treatment) or repeated withdrawal events (i.p. treatment), based on pharmacokinetic evidence in rats (Friedman et al, 1986; Fernandes et al, 1999; Allison et al, 2002) and behavioral evidence in mice that repeated withdrawal from DZP results in amelioration of the anxiogenic effects of withdrawal (Dunworth and Stephens, 1998; Ward and Stephens, 1998).

\section{Diazepam Withdrawal-Induced Changes in AMPA Receptor Binding and GluR1 and GluR2 mRNA Expression: Relevance to AMPA Receptor Function}

The results of these autoradiography and ISH studies indicate differential patterns of regionally selective changes in AMPA receptor binding and AMPA receptor subunit mRNA expression in the rats withdrawn from the two different DZP treatment regimens, indicating that these may be neural correlates of the differential behavioral effects of DZP withdrawal. For convenience, the results are discussed according to the brain regions where these patterns of change in AMPA receptor characteristics occurred, namely hippocampus, amygdala, limbic-associated cortex, thalamus, and striatum.

In general, the regional changes in AMPA receptor binding did not correlate with changes in AMPA receptor subunit expression. There are a number of possible explanations for this apparent anomaly: firstly, the time point at which these measurements were taken. Both protein and mRNA were measured in adjacent sections from the same animal at the same particular time point following DZP withdrawal. It is likely that the changes in mRNA precede the changes in receptor protein; thus, it is not surprising that in some regions, there are changes in subunit mRNA without corresponding changes in receptor binding (eg amygdala). Secondly, although changes in subunit expression may result in altered functionality of the AMPA receptor, this would not necessarily be reflected as altered AMPA binding since the ligand employed does not appear to distinguish between these subunits. This is based on evidence that the patterns of distribution of the subunit proteins and binding of $\left[{ }^{3} \mathrm{H}\right] \mathrm{Ro} 488587$ in rat brain overlap (Mutel et al, 1998), thus indicating that the radioligand does not preferentially bind to any one of the subunits.

Nevertheless, the data do suggest that AMPA receptor function may be altered in a regionally selective fashion during DZP withdrawal since the functional properties of heteromeric AMPA receptors are determined by their subunit composition. The GluR1 receptor subunit has phosphorylation sites, which when activated increase current flow through the receptor (Keinanen et al, 1990; Roche et al, 1996; Banke et al, 2000). It also has a role in synaptic targeting and/or trafficking of AMPA receptors through interactions with some of the receptor-associated proteins such as SAP97 (Leonard et al, 1998), which may function to modulate synaptic AMPA receptor dynamics and thus mechanisms of synaptic plasticity. The GluR1 subunit has also been shown to interact with an inhibitory G protein in cortical neurons (Wang et al, 1997), thus indicating a metabotropic function of the AMPA receptor. Reduction in levels of the GluR1 subunit, as noted in cortical regions in the present study, might therefore result in either excitatory or inhibitory effects on AMPA receptormediated neurotransmission.

The GluR2 subunit confers $\mathrm{Ca}^{2+}$ impermeability on the AMPA receptor (Boulter et al, 1990; Pellegrini-Giampietro et al, 1997). The overall increases in GluR2 mRNA in the caudate putamen and the nucleus accumbens might therefore be a neuroprotective adaptation to reduce $\mathrm{Ca}^{2+}$ permeability and hence neuronal excitation through the AMPA receptor in the group that appeared to have become resistant to the repeated experience of DZP withdrawal (i.p. treatment regime; Figure 5). Likewise, the overall decrease in amygdaloid GluR2 expression may indicate an excitatory effect in the group (s.c. treatment regime) experiencing withdrawal anxiety (Figure 5).

\section{Hippocampus}

Both treatment regimes altered $\left[{ }^{3} \mathrm{H}\right] \mathrm{Ro} 488587$ binding in the hippocampus overall but in opposite directions. There appeared to be an overall reduction in the i.p. DZP group and an overall increase in the s.c. group of AMPA receptor binding, consistent with the differential anxiety responses produced by these treatment regimes. No corresponding alterations were detected in levels of mRNA for either the GluR1 or the GluR2 subunits of the AMPA receptor in the hippocampus.

The hippocampal formation has been implicated in anxiety (Gray, 1987; Pratt, 1992; Pratt et al, 1988), kindling, and epileptogenic behavior (eg Mody and Heinemann, 1987; Gale, 1992). There is a close inter-relationship between GABA and glutamate transmission in the hippocampus, such that if GABAergic inhibition is removed, glutamatergic polysynaptic responses mediated by AMPA and NMDA receptors are evoked (Crepel et al, 1997). Consistent with this evidence and the proposed glutamatergic hypothesis of BZ withdrawal, there may be an 'unmasking' of glutamatergic processes during DZP withdrawal-induced anxiety, as observed following the s.c. treatment in this study. This may be apparent as the increase in hippocampal AMPA binding 
demonstrated and could result from the removal of GABAergic inhibition following drug withdrawal. This is further supported by recent mouse studies in our laboratories in which there was an increase in AMPA receptor binding in the hippocampus following a single withdrawal from chronic DZP (Allison et al, 2005). These data are also consistent with evidence of increased AMPA binding in the hippocampus $48 \mathrm{~h}$ following cessation of 7-day chronic treatment with high doses of flurazepam (Van Sickle and Tietz, 2002) and increases in hippocampal AMPA receptormediated transmission and withdrawal anxiety $24 \mathrm{~h}$ following flurazepam withdrawal (Van Sickle et al, 2004). Furthermore, $96 \mathrm{~h}$ following a chronic escalating dose regime $(5-20 \mathrm{mg} / \mathrm{kg}$ oral DZP three times per day), withdrawal anxiety and increases in hippocampal and cortical GluR1 subunit mRNA and protein occurred (Izzo et al, 2001). However, it is difficult to compare directly the results of these studies to those in the present study due to differences in the experimental protocol used (including rat strain used, BZ employed, dose, length of chronic treatment, and withdrawal time point chosen). This is particularly important in light of the fact that the present study demonstrates that the same $\mathrm{BZ}$ administered via different injection routes produces differential effects on withdrawal anxiety and AMPA receptor properties.

Interestingly, the chronic i.p. protocol that did not evoke withdrawal anxiety in the present study produced decreases rather than increases in AMPA receptor binding. Assuming that this i.p. protocol evokes similar repeated withdrawal experiences as that in mice, resulting in reduced anxiety but enhanced seizure susceptibility (Ward and Stephens, 1998; Dunworth and Stephens, 1998), it is conceivable that the reduction of hippocampal $\left[{ }^{3} \mathrm{H}\right] \mathrm{Ro} 488587$ binding to AMPA receptors is a result of a compensatory neuroprotective response to further increases in excitatory activity. Reduced numbers of AMPA receptors might therefore protect this structure from potential damage due to increased seizure susceptibility.

The present data do not allow a distinction to be made between $\left[{ }^{3} \mathrm{H}\right] \mathrm{Ro} 48 \quad 8587$ binding changes resulting from alterations in AMPA receptor number or affinity, since a single nonsaturating concentration around the $K_{\mathrm{D}}$ of the radioligand was employed. However, ligand binding affinity is partly dependent on receptor subunit composition, and $\left[{ }^{3} \mathrm{H}\right] \mathrm{Ro} 488587$ does not appear to preferentially bind to any one of the AMPA receptor subunits (Mutel et al, 1998). It therefore remains a possibility that the affinity of the AMPA receptor for $\left[{ }^{3} \mathrm{H}\right] \mathrm{Ro} 488587$ would be unchanged if subunit switching occurred as a consequence of chronic treatment and withdrawal. Thus, in this case, the changes observed in $\left[{ }^{3} \mathrm{H}\right] \mathrm{Ro} 488587$ binding in the present study would be more likely to be the result of alterations in AMPA receptor number rather than affinity changes. A further possibility is that the binding changes may be a reflection of alterations in the dynamic recycling of the AMPA receptor.

An additional point to note is that there was a two- to three-fold difference in the control values of specific $\left[{ }^{3} \mathrm{H}\right] \mathrm{Ro} 488587$ binding for the i.p. and s.c. groups. While these two experiments were carried out at different times as already detailed in the Methods section, no simple explanation for this difference is apparent since the same batch of radioligand and the same protocol were used in both. The autoradiography protocol that we have employed is sufficient to reduce levels of endogenous glutamate in the brain sections before incubation with $\left[{ }^{3} \mathrm{H}\right] \mathrm{Ro} 48$ 8587. This is based on results of previous experiments investigating the effect of osmotic shock of the brain sections, which revealed no additional binding of $\left[{ }^{3} \mathrm{H}\right] \mathrm{Ro} 488587$ indicating maximal washout of endogenous competing glutamate from the sections using the protocol employed in these experiments (C Allison, unpublished results). Additionally, both the i.p. and s.c. groups in both experiments were handled and injected on a daily basis, making this factor an unlikely cause of the difference in control levels of radioligand binding. It is also important to reiterate that the $\left[{ }^{3} \mathrm{H}\right] \mathrm{Ro} 48$ 8587 binding data from each experiment was analyzed separately, as direct statistical comparisons between the i.p. and s.c. groups was inappropriate since the data came from separate experiments.

\section{Amygdala}

Significant effects of withdrawal from s.c. but not i.p. DZP on GluR1 and GluR2 mRNA expression in the amygdala overall (medial, basolateral, and lateral amygdala) were detected in this study. No corresponding alterations were detected in levels of $\left[{ }^{3} \mathrm{H}\right] \mathrm{Ro} 488587$ binding to the AMPA receptor.

In similarity with the hippocampus, the amygdala has functional overlaps with respect to anxiety behaviors and seizure activity. Stimulation of the amygdala in animals provokes fear behaviors and defensive reactions (see Davis, 1992a, b, 1994 for reviews) and amygdaloid lesions reduce the expression of signs of fear and anxiety (Treit et al, 1993). The amygdala has also been strongly implicated in mediating the anxiolytic effects of BZs (Hodges et al, 1987; Green and Vale, 1992). Notably, local infusion of BZs in the basolateral and lateral nuclei of the amygdala produces anxiolytic effects in animal models of anxiety (ScheelKruger and Petersen, 1982; Costall et al, 1989).

Again in similarity with the hippocampus, there is a close relationship between glutamate and GABA transmission in the amygdala (Wang et al, 2001). This relationship might account for the potent anxiolytic effects of drugs that facilitate GABA (eg BZs) and also suggests that modulation of AMPA receptors may have a similar anxiolytic effect. Indeed, local infusion of AMPA receptor antagonists into the amygdala produces an anxiolytic effect (Mesches et al, 1996) as does systemic administration (Swedberg et al, 1995; Kotlinska and Liljequist, 1998).

The demonstration of changes in mRNA expression of the GluR1 and GluR2 AMPA receptor subunits in the amygdala of rats withdrawn from s.c. DZP in the present study may therefore be related to the expression of anxiety-related behaviors measured in this group of rats. The particular subunit composition of native AMPA receptors can have profound consequences for receptor function (Wenthold et al, 1992), which then has further consequences for synaptic function and plasticity. The fact that no such changes were observed in the rats that did not experience withdrawal anxiety (chronic i.p. group) adds weight to the idea that the observed changes in GluR1 and GluR2 mRNA expression in the s.c. group may reflect functional changes 
in amygdalar AMPA receptors, which are in part responsible for the expression of anxiogenic behavior on withdrawal.

\section{Cortical Regions}

The most apparent effects of the DZP treatment regimes on AMPA receptor characteristics were in limbic-associated cortical regions. In the s.c. group experiencing withdrawal anxiety, there were significant overall reductions in GluR1 mRNA expression in the retrosplenial and insular cortices. In the i.p. group, changes in GluR1 mRNA expression were particularly marked in the AI (Figure 4). Changes in the agranular insular and retrosplenial cortex may be related to the emotional state or level of anxiety in the animals since these regions have been shown to be involved in various memory and emotional functions and to be activated by a range of anxiogenic stimuli (Beck and Fibiger, 1995; Yokoyama and Sasaki, 1999; Bruijnzeel et al, 1999; Del Cano et al, 2000; Shibata, 2000). Thus, it is conceivable that alterations in AMPA receptor function may be important in both treatment groups. The absence of withdrawal anxiety in the i.p. group could indicate a process whereby there is behavioral resistance to this aspect of withdrawal, which may be predicted to recruit areas such as the AI.

\section{Thalamus}

Significant effects of withdrawal from s.c. but not i.p. DZP on $\left[{ }^{3} \mathrm{H}\right] \mathrm{Ro} 488587$ binding in the thalamus overall (reticular (Rt) and laterodorsal (LDVL) nuclei) were detected in this study (Figure 3). Levels of mRNA expression for the GluR1 and GluR2 AMPA receptor subunits in the thalamus are very low and were therefore not measured in this study.

The Rt is composed of GABAergic cells that receive synapses from both thalamocortical and corticothalamic fibers, and is thought to provide an inhibitory 'brake' on information travelling in these fibers. The LDVL through its connections with various cortical and hippocampal regions also provides a means through which sensory information can access the limbic system.

The differential pattern of changes in $\left[{ }^{3} \mathrm{H}\right] \mathrm{Ro} 488587$ binding in the Rt and LDVL of rats withdrawn from i.p. or s.c. DZP in the present study might again reflect the differential anxiogenic profile of these groups of rats and could indicate the involvement of AMPA receptors in specific nuclei of the thalamus in anxiety behavior following DZP withdrawal. Thus, in the s.c. DZP group, increased AMPA receptor binding may correspond to the 'unmasking' of latent excitatory mechanisms in the thalamus, while in the i.p. DZP group, a compensatory downregulation of the system may have taken place due to repeated withdrawals, such that $\left[{ }^{3} \mathrm{H}\right] \mathrm{Ro} 488587$ binding is now restored to control levels (Figure 3 ). Consistent with these results, we have recently reported increases in AMPA receptor binding in these thalamic nuclei in mice experiencing a single withdrawal from chronic DZP (Allison et al, 2005).

\section{Striatum}

Significant effects of withdrawal from i.p. but not s.c. DZP on GluR2 mRNA expression in the striatum overall (dorsolateral caudate (DLCPu), AcC, and AcSh) were detected in this study. No corresponding alterations were detected in GluR1 mRNA expression levels or $\left[{ }^{3} \mathrm{H}\right] \mathrm{Ro} 48$ 8587 binding in these two groups of rats. The nucleus accumbens is involved in the reinforcing effects of drugs and in responses to stressful stimuli. Furthermore, anxiogenic drugs such as inverse $\mathrm{BZ}$ agonists increase nucleus accumbens dopamine activity (McCullough and Salamone, 1992). Alterations in striatal GluR2 expression could potentially reflect neuroadaptive compensatory processes that occur in response to the repeated withdrawal experiences of the i.p. group.

In summary, the results of this investigation provide support for the hypothesis that changes in the AMPA receptor system contribute to the neuroadaptive mechanisms underlying the process of BZ dependence. Moreover, these data suggest regionally selective and differential neuroadaptive processes at the level of the AMPA receptor in rats withdrawn from two different DZP treatment regimes. Animals withdrawn from a chronic s.c. DZP treatment regime, which delivers relatively constant plasma levels of the drug, displayed withdrawal anxiety. Brains from these animals showed increased AMPA receptor binding in the hippocampus and thalamus together with decreased subunit expression in the amygdala (GluR1 and GluR2) and limbic-associated cortex (GluR1). This suggests that AMPA receptor characteristics in these regions, particularly the amygdala, may contribute to the expression of anxiety and aversion during DZP withdrawal. Despite the fact that no withdrawal anxiety was detectable in the chronic i.p. group, these animals showed altered AMPA receptor binding and subunit gene expression. Changes in gene expression were apparent in the agranular insular cortex (GluR1) and the striatum (GluR2) although the reduced AMPA binding in the hippocampus was in the opposite direction to that occurring after s.c. DZP and no changes were detected in the amygdala. Based on pharmacokinetic evidence (Friedman et al, 1986), these animals may have undergone repeated withdrawal experiences, which made them more resistant to withdrawal anxiety. Hence, the changes in AMPA receptor characteristics in these regions may have contributed to these neuroadaptive alterations in emotional state.

Further understanding of the underlying mechanisms in these brain regions would be assisted by corresponding measurements of GluR1 and GluR2 subunit protein using immunohistochemical methods and information on how changes in the relative levels of particular AMPA receptor subunits affect the function of the assembled AMPA receptors in the identified brain areas in vivo. Functional electrophysiological experiments would also help to clarify whether these changes in AMPA subunit mRNA and receptor binding are accompanied by excitatory or inhibitory effects on AMPA receptor-mediated neurotransmission in the brain regions identified in the present study.

We have not sought to address alterations in other aspects of withdrawal such as seizure susceptibility in the present study, but it is conceivable that some of the changes observed may relate to this aspect of DZP withdrawal. Nevertheless, the present results highlight how different chronic DZP treatments can evoke different neuroadaptive processes at the behavioral level and at the level of the 
AMPA receptor. This emphasizes the importance of determining behavioral and biochemical measurements in concert in order to make informed interpretations about the neurochemical mechanisms that may underlie particular aspects of dependence.

\section{REFERENCES}

Albin RL, Makowiec RL, Hollingsworth ZR, Dure IV LS, Penney JB, Young AB (1992). Excitatory amino acid binding sites in the basal ganglia of the rat: a quantitative autoradiography study. Neuroscience 46: 35-48.

Allison C (2002). Investigations of regional changes in AMPA receptor characteristics during diazepam withdrawal. PhD thesis, University of Strathclyde.

Allison C, Claase LA, Pratt JA (2002). Diazepam withdrawalinduced anxiety and place aversion in the rat: differential effects of two chronic diazepam treatment regimes. Behav Pharmacol 13: 417-425.

Allison C, Pratt JA (2003). Neuroadaptive processes in GABAergic and glutamatergic systems in benzodiazepine dependence. Pharmacol Therap 98: 171-195.

Allison C, Pratt JA, Ripley TL, Stephens DN (2005). AMPA receptor autoradiography in mouse brain following single and repeated withdrawal from diazepam. Eur J Neurosci 21: 1045-1056.

Arnot MI, Davies M, Martin IL, Bateson AN (2001). GABA receptor gene expression in rat cortex: differential effects of two chronic diazepam treatment regimes. J Neurosci Res 64: 617-625.

Baldwin H, File SE (1989). Flumazenil prevents the development of chlordiazepoxide withdrawal in rats tested in the social interaction test of anxiety. Psychopharmacology 97: 424-426.

Banke TG, Bowie D, Lee H, Huganir RL, Schousboe A, Traynelis SF (2000). Control of GluR1 AMPA receptor function by cAMPdependent protein kinase. J Neurosci 20: 89-102.

Beck CHM, Fibiger HC (1995). Conditioned fear-induced changes in behaviour and in the expression of the immediate early gene c-fos: with and without diazepam pre-treatment. J Neurosci 15: 709-720.

Boulter J, Hollmann M, O’Shea-Greenfield A, Hartley M, Deneris E, Maron C et al (1990). Molecular cloning and functional expression of glutamate receptor subunit genes. Science 249: 1033-1037.

Brett RR, Pratt JA (1995). Changes in BZ-GABA receptor coupling in an accumbens-habenula circuit after chronic diazepam treatment. Br J Pharmacol 116: 2375-2384.

Bruijnzeel AW, Stam R, Compaan JC, Croiset G, Akkermans LMA, Olivier B et al (1999). Long-term sensitisation of fos-responsivity in the rat central nervous system after a single stressful experience. Brain Res 819: 15-22.

Costall B, Jones BJ, Kelly ME, Naylor RJ, Onaivi ES, Tyers MB (1990). Sites of action of ondansetron to inhibit withdrawal from drugs of abuse. Pharmacol Biochem Behav 36: 97-104.

Costall B, Kelly ME, Naylor RJ, Onaivi ES, Tyers MB (1989). Neuroanatomical sites of action of $5-\mathrm{HT}_{3}$ receptor agonist and antagonists for alteration of aversive behaviour in the mouse. $\mathrm{Br}$ J Pharmacol 96: 325-332.

Crepel V, Khazipov R, Ben-Ari Y (1997). Blocking $\mathrm{GABA}_{\mathrm{A}}$ inhibition reveals AMPA- and NMDA-receptor mediated polysynaptic responses in the CA1 region of the hippocampus. J Neurophysiol 77: 2071-2082.

Cruz AP, Frei F, Graeff FG (1994). Ethopharmacological analysis of rat behaviour on the elevated plus-maze. Pharmacol Biochem Behav 49: 171-176.

Davis M (1992a). The role of the amygdala in fear and anxiety. Annu Rev Neurosci 15: 353-375.

Davis M (1992b). The role of the amygdala in conditioned fear. In: Aggleton JP (ed). The Amygdala: Neurobiological Aspects of
Emotion, Memory and Mental Dysfunction. Wiley-Liss Inc: New York. pp 255-305.

Davis M, Rainnie D, Cassell M (1994). Neurotransmission in the rat amygdala related to fear and anxiety. Trends Neurosci 17: 208-214.

Dawson GR, Tricklebank MD (1995). Use of the elevated plus-maze in the search for novel anxiolytic agents. Trends Pharmacol Sci 16: 33-36.

Del Cano GG, Gerrikagoitia I, Martinez-Millan L (2000). Morphology and topographical organisation of the retrospleniocollicular connection: a pathway to relay contextual information from the environment to the superior colliculus. J Comp Neurol 425: 393-408.

Dunworth SJ, Mead AN, Stephens DN (2000). Previous experience of withdrawal from chronic diazepam ameliorates the aversiveness of precipitated withdrawal and reduces withdrawal-induced c-fos expression in nucleus accumbens. Eur J Neurosci 12: 1501-1508.

Dunworth SJ, Stephens DN (1998). Sensitisation to repeated withdrawal, in mice treated chronically with diazepam, is blocked by an NMDA receptor antagonist. Psychopharmacology 136: 308-310.

Fernandes C, Arnot MI, Irvine EE, Bateson AN, Martin IL, File SE (1999). The effect of treatment regimen on the development of tolerance to the sedative and anxiolytic effects of diazepam. Psychopharmacology 145: 251-259.

Fernandes C, File SE (1996). The influence of open arm ledges and maze experience in the elevated plus-maze. Pharmacol Biochem Behav 54: 31-40.

File SE (1985). Tolerance to the behavioural actions of benzodiazepines. Neurosci Biobehav Rev 9: 113-121.

File SE (1989). Chronic diazepam treatment: effect of dose on development of tolerance and incidence of withdrawal in an animal test of anxiety. Hum Psychopharmacol 4: 59-63.

File SE, Fernandes C (1994). Dizocilpine prevents the development of tolerance to the sedative effects of diazepam in rats. Pharmacol Biochem Behav 47: 823-826.

Friedman H, Abernethy DR, Greenblatt DJ, Shader RI (1986). The pharmacokinetics of diazepam and desmethyldiazepam in rat brain and plasma. Psychopharmacology 88: 267-270.

Gale K (1992). Subcortical structures and pathways involved in convulsive seizure generation. J clin Neurophysiol 9: 264-277.

Gonsalves SF, Gallager DW (1987). Time course for development of anti-convulsant tolerance and GABA ergic subsensitivity after chronic diazepam. Brain Res 405: 94-99.

Gray JA (1987). The Neuropsychology of Anxiety. An Enquiry in to the Functions of the Septohippocampal System. Oxford Science Publications: New York.

Green S, Vale AL (1992). Role of amygdaloid nuclei in the anxiolytic effects of benzodiazepines in rats. Behav Pharmacol 3: 261-264.

Handley SL, Mithani S (1984). Effects of alpha-adrenoceptor agonists and antagonists in a maze exploration model of 'fear'motivated behaviour. Naunyn-Schmeideberg's Arch Pharmacol 327: $1-5$.

Heninger C, Saito N, Tallman JF, Garrett KM, Vitek MP, Duman RS et al (1990). Effects of continuous diazepam administration on GABAA subunit mRNA in rat brain. J Mol Neurosci 2: 101-107.

Hodges H, Green S, Glenn B (1987). Evidence that the amygdala is involved in benzodiazepine and serotonergic effects on punished responding but not on discrimination. Psychopharmacology 92: 491-504.

Holt RA, Bateson AN, Martin IL (1996). Chronic treatment with diazepam or abecarnil differentially affects the expression of $\mathrm{GABA}_{\mathrm{A}}$ receptor subunit mRNAs in the rat cortex. Neuropharmacology 35: 1457-1463.

Holt RA, Bateson AN, Martin IL (1999). Decreased GABA enhancement of benzodiazepine binding after a single dose of diazepam. J Neurochem 72: 2219-2222. 
Impagnatiello F, Pesold C, Longone $\mathrm{P}$, Caruncho $\mathrm{H}$, Fritschy JM, Costa E et al (1996). Modifications of gamma-aminobutyric acidA receptor subunit expression in rat neocortex during tolerance to diazepam. Mol Pharmacol 49: 822-831.

Izzo E, Auta J, Impagnatiello F, Pesold C, Guidotti A, Costa E (2001). Glutamic acid decarboxylase and glutamate receptor changes during tolerance and dependence to benzodiazepines. Proc Natl Acad Sci USA 98: 3483-3488.

Kang I, Miller LG (1991). Decreased GABAA receptor subunit mRNA concentrations following chronic lorazepam administration. Br J Pharmacol 103: 1285-1287.

Keinanen K, Wisden W, Sommer B, Werner P, Herb A, Verdoorn TA et al (1990). A family of AMPA-selective glutamate receptors. Science 249: 556-560.

Koff JM, Pritchard GA, Greenblatt DJ, Miller LG (1997). The NMDA receptor competitive antagonist CPP modulates benzodiazepine tolerance and discontinuation. Pharmacology 55: 217-227.

Kotlinska J, Liljequist S (1998). The putative AMPA receptor antagonist, LY326325, produces anxiolytic-like effects without altering locomotor activity in rats. Pharmacol Biochem Behav 60: 119-124.

Laurie DJ, Pratt JA (1989). Local cerebral glucose utilisation following subacute and chronic diazepam treatment: differential tolerance. Brain Res 504: 101-111.

Laurie DJ, Pratt JA (1993). Flumazenil induces localised increases in glucose utilisation during diazepam withdrawal in rats. Brain Res 631: 277-286.

Leonard AS, Davare MA, Horne MC, Garner CC, Hell JW (1998). SAP97 is associated with the alpha-amino-3-hydroxy-5-methylisoxazole-4-propionic acid receptor GluR1 subunit. J Biol Chem 273: 19518-19524.

McCullough LD, Salamone JD (1992). Anxiogenic drugs beta-CCE and FG7142 increase extracellular dopamine levels in nucleus accumbens. Psychopharmacologia 109: 379-382.

Mesches MH, Bianchin M, McGaugh JL (1996). The effects of intraamygdala infusion of the AMPA receptor antagonist CNQX on retention performance following aversive training. Neurobiol Learn Mem 66: 324-340.

Mody I, Heinemann U (1987). NMDA receptors of dentate gyrus granule cells participate in synaptic transmission following kindling. Nature 326: 701-704.

Monaghan DT, Yao D, Cotman CW (1984). Distribution of $\left[{ }^{3} \mathrm{H}\right]$ AMPA binding sites in rat brain as determined by quantitative autoradiography. Brain Res 324: 160-164.

Mutel V, Trube G, Klingelschmidt A, Messer J, Bleuel Z, Humbel U et al (1998). Binding characteristics of a potent AMPA receptor antagonist $\left[{ }^{3} \mathrm{H}\right] \mathrm{Ro} 488587$ in rat brain. J Neurochem 71: 418-426.

Nielsen EO, Cha JH, Honore T, Penney JB, Young AB (1988). Thiocyanate stabilizes AMPA binding to the quisqualate receptor. Eur J Pharmacol 157: 197-203.

Nielsen EO, Drejer J, Cha J-H J, Young AB, Honore T (1990). Autoradiographic characterisation and localisation of quisqualate binding sites in rat brain using the antagonist $\left[{ }^{3} \mathrm{H}\right]$-cyano-7-nitroquinoxaline-2,3-dione: comparison with $(R, S)$ - $\left[{ }^{3} \mathrm{H}\right] \alpha$-amino-3-hydroxy-5-methyl-4-isoxazole-propionic acid binding sites. J Neurochem 54: 686-695.

Nutt DJ (1986). Benzodiazepine dependence in the clinic: reason for anxiety. Trends Neurosci 8: 457-460.

O'Donovan MC, Buckland PR, McGuffin P (1992b). Levels of $\mathrm{GABA}_{\mathrm{A}}$ receptor subunit mRNA in rat brain following flurazepam treatment. J Psychopharmacol 6: 364-369.

O'Donovan MC, Buckland PR, Spurlock G, McGuffin P (1992a). Bi-directional changes in the levels of messenger RNAs encoding gamma-aminobutyric acidA receptor alpha subunits after flurazepam treatment. Eur J Pharmacol 226: 335-341.
Olsen RW, Szamraj O, Houser CR (1987). [ $\left.{ }^{3} \mathrm{H}\right] \mathrm{AMPA}$ binding to glutamate receptor subpopulations in rat brain. Brain Res 402: 243-254.

Paxinos G, Watson C (1997). The Rat Brain in Stereotaxic Coordinates, 3rd edn. Academic Press: London.

Pellegrini-Giampietro DE, Bennett MV, Zukin RS (1991). Differential expression of three glutamate receptor genes in developing rat brain: An in situ hybridization study. Proc Natl Acad Sci USA 88: 4157-4161.

Pellegrini-Giampietro DE, Gorter JA, Bennett MV, Zukin RS (1997). The GluR2 (GluR-B) hypothesis: Ca(2+)-permeable AMPA receptors in neurological disorders. Trends Neurosci 20: $464-470$

Pellow S, Chopin P, File SE, Briley M (1985). Validation of open: closed arm entries in an elevated plus-maze as a measure of anxiety in the rat. J Neurosci Methods 14: 149-167.

Pratt JA (1992). The neuroanatomical basis of anxiety. Pharmacol Ther 55: 149-181.

Pratt JA, Brett RR, Laurie DJ (1998). Benzodiazepine dependence: from neural circuits to gene expression. Pharmacol Biochem Behav 59: 925-934.

Pratt JA, Laurie DJ, McCulloch J (1988). The effects of FG 7142 upon local cerebral glucose utilization suggest overlap between limbic structures important in anxiety and convulsions. Brain Res 475: 218-231.

Rainbow TC, Wieczorek CM, Halpain S (1984). Quantitative autoradiography of binding sites for $\left[{ }^{3} \mathrm{H}\right] \mathrm{AMPA}$, a structural analogue of glutamic acid. Brain Res 309: 173-177.

Rex A, Sondern U, Voigt JP, Franck S, Fink H (1996). Strain differences in fear-motivated behavior of rats. Pharmacol Biochem Behav 54: 107-111.

Roche KW, O'Brien RJ, Mammen AL, Bernhardt J, Huganir RL (1996). Characterization of multiple phosphorylation sites on the AMPA receptor GluR1 subunit. Neuron 16: 1179-1188.

Rodgers RJ, Johnson NJ (1995). Factor analysis of spatiotemporal and ethological measures in the murine elevated plus-maze test of anxiety. Pharmacol Biochem Behav 52: 297-303.

Scheel-Kruger J, Petersen EN (1982). Anticonflict effects of the benzodiazepines mediated by a GABAergic mechanism in the amygdala. Eur J Pharmacol 82: 115-116.

Shepherd JK, Grewal SS, Fletcher A, Bill DJ, Dourish CT (1994). Behavioural and pharmacological characterisation of the elevated 'zero-maze' as an animal model of anxiety. Psychopharmacology 116: 56-64.

Shibata $\mathrm{H}$ (2000). Organisation of retrosplenial cortical projections to the laterodorsal thalamic nucleus in the rat. Neurosci Res 38: 303-311.

Stephens DN (1995). A glutamatergic hypothesis of drug dependence. Behav Pharmacol 6: 425-446.

Steppuhn KG, Schneider HH, Turski L, Stephens DN (1993). Long term treatment with abecarnil does not induce diazepam-like dependence in mice. J Pharmacol Exp Ther 264: 1395-1400.

Steppuhn KG, Turski L (1993). Diazepam dependence prevented by glutamate antagonists. Proc Natl Acad Sci 90: 6889-6893.

Swedberg MD, Jacobsen P, Honore T (1995). Anticonvulsant, anxiolytic and discriminative effects of the AMPA antagonist 2,3-dihydroxy-6-nitro-7-sulfamoyl-benzo( $f$ quinoxaline (NBQX). J Pharmacol Exp Ther 274: 1113-1121.

Treit D, Pesold C, Rotzinger S (1993). Dissociating the anti-fear effects of septal and amygdaloid lesions using two pharmacologically validated models of rat anxiety. Behav Neurosci 107: 770-785.

Tietz EI, Huang X, Weng X, Rosenberg HC, Chiu TH (1993). Expression of $\alpha_{1}, \alpha_{5}$ and $\gamma_{2} \mathrm{GABA}_{\mathrm{A}}$ receptor subunit mRNAs measured in situ in rat hippocampus and cortex following chronic flurazepam. J Mol Neurosci 4: 277-292.

Tsuda M, Shimizu N, Yajima Y, Suzuki T, Misawa M (1998a). Hypersusceptibility to DMCM-induced seizures during 
diazepam withdrawal in mice: evidence for upregulation of NMDA receptors. Naunyn-Schmiedeberg's Arch Pharmacol 357: 309-315.

Tsuda M, Suzuki T, Misawa M (1998b). NMDA receptor antagonists potently suppress the spontaneous withdrawal signs induced by discontinuation of long-term diazepam treatment in Fischer 344 rats. Brain Res 790: 82-90.

Van Sickle BJ, Cox AS, Schak K, John Greenfield Jr L, Tietz EI (2002). Chronic benzodiazepine administration alters hippocampal CA1 neuron excitability: NMDA receptor function and expression. Neuropharmacology 43: 595-602.

Van Sickle BJ, Tietz EI (2002). Selective enhancement of AMPA receptor-mediated function in hippocampal CA1 neurons from chronic benzodiazepine-treated rats. Neuropharmacology 43: 11-27.

Van Sickle BJ, Xiang K, Tietz EI (2004). Transient plasticity of hippocampal CA1 neuron glutamate receptors contributes to benzodiazepine withdrawal-anxiety. Neuropsychopharmacology 29: 1994-2006.

Walker MC, Tong X, Brown S, Shorvon SD, Patsalos PN (1998). Comparison of single- and repeated-dose pharmacokinetics of diazepam. Epilepsia 39: 283-289.

Wang Y, Small DL, Stanimirovic DB, Morley P, Durkin JP (1997). AMPA receptor-mediated regulation of a Gi-protein in cortical neurons. Nature 389: 502-504.

Wang C, Wilson WA, Moore SD (2001). Role of NMDA, nonNMDA and GABA receptors in signal propagation in the amygdala formation. J Neurophysiol 86: 1422-1429.
Ward BO, Stephens DN (1998). Sensitisation of withdrawal signs following repeated withdrawal from a benzodiazepine: differences between measures of anxiety and seizure sensitivity. Psychopharmacology 135: 342-352.

Wenthold RJ, Yokotani N, Doi K, Wada K (1992). Immunochemical characterisation of the non-NMDA glutamate receptor using subunit-specific antibodies. Evidence for a hetero-oligomeric structure in rat brain. $J$ Biol Chem 267: 501-507.

Wisden W, Morris BJ (1994). In situ hybridisation with synthetic probes. In: Wisden W, Morris BJ (eds). In Situ Hybridisation Protocols for the Brain. Academic Press: London. pp 9-34.

Woods JH, Katz JL, Winger G (1992). Benzodiazepines: use, abuse and consequences. Pharmacol Rev 44: 151-338.

Woods JH, Katz JL, Winger G (1995). Abuse and therapeutic use of benzodiazepines and benzodiazepine-like drugs. In: Bloom FE, Kupfer DJ (eds). Psychopharmacology: The Fourth Generation of Progress. Raven Press: New York. pp 1777-1790.

Wright IK, Heaton M, Upton N, Marsden CA (1992). Comparison of acute and chronic treatment of various serotonergic agents with those of diazepam and idazoxan in the rat elevated X-maze. Psychopharmacology 107: 405-414.

Yokoyama C, Sasaki K (1999). Regional expression of fos-like immunoreactivity in rat cerebral cortex after stress, restraint and intraperitoneal lipopolysaccharide. Brain Res 816: 267-275.

Zhao TJ, Chiu TH, Rosenberg HC (1994). Reduced expression of $\mathrm{GABA}_{\mathrm{A}}$ /benzodiazepine receptor $\gamma_{2}$ and $\alpha_{5}$ subunit mRNAs in brain regions of flurazepam treated rats. Mol Pharmacol 45: $657-663$. 